\title{
Optimized MoP with Pseudo-Single-Atom Tungsten for Efficient
}

\section{Hydrogen Electrocatalysis}

Changli Chen ${ }^{1}$, Wenjia $\mathrm{Luo}^{2}$, Haijing $\mathrm{Li}^{3}$, Tao Hu${ }^{4}$, Yizhou Zhao ${ }^{1}$, Zipeng Zhao, Xiaolong Sun ${ }^{6}$, Huachao Zai ${ }^{1}$, Yifei Qi ${ }^{1}$, Menghao Wu ${ }^{1}$, Yuanyuan Dong' ${ }^{1}$, Juncai Don ${ }^{3}$, Wenxing Chen ${ }^{1}$, Xiaoxing $\mathrm{Ke}^{4}$, Manling Sui ${ }^{4}$, Liqiang Zhang ${ }^{7}$, Qi Chen ${ }^{1}$, Ziyu Wang*6, Enbo Zhu*1, Yujing Li*1, Yu Huang ${ }^{5}$

1. Dr. Changli Chen, Dr. Y izhou Zhao, Yifei. Qi, Dr. Huachao. Zai, Menghao Wu, Dr. Yuanyuan Dong, Prof. Qi Chen, Dr. Enbo Zhu, Prof. Yujing Li

Beijing Key Laboratory of Construction Tailorable Advanced Functional Materials and Green Applications, Experimental Center of Advanced Materials

School of Materials Science and Engineering

Beijing Institute of Technology

Beijing, 100081, P.R. China

E-mail: yjli@bit.edu.cn

E-mail: enbozhu@gmail.com

2. Prof. Wenjia Luo

School of Chemistry and Chemical Engineering

Southwest Petroleum University

Chengdu, 610500, P.R. China

3. Dr. Haijing Li, Prof. Juncai Dong

Beijing Synchrotron Radiation Facility

Institute of High Energy Physics

Chinese Academy of Sciences

Beijing 100049, China

4. Tao Hu, Prof. Xiaoxing Ke, Prof. Manling Sui

Beijing University of Technology

Institute of Microstructure and Property of Advanced Materials

Beijing, 100124, P.R. China

5. Dr. Zipeng Zhao, Prof. Yu Huang

Department of Materials Science and Engineering

University of California, Los Angeles

Los Angeles, 90095, United States

6. Dr. Xiaolong Sun, Prof. Ziyu Wang

The Institute of Technological Sciences, Wuhan University

Wuhan 430072, China

E-mail: zywang@whu.edu.cn

7. Prof. Liqiang Zhang

Clean Nano Energy Center, State Key Laboratory of Metastable Materials Science and Technology, Yanshan University

Qinhuangdao 066004, China 
Contents:

- Experimental Section

- Materials

๑Synthesis of $\mathrm{W}_{0.25} \mathrm{Mo}_{0.75} \mathrm{P} / \mathrm{PNC}$ catalysts

-Characterizations

- Foundational characterization

-X-ray absorption data analysis

$\bullet \mathrm{H}_{2}$-TPD test

-Electrochemical measurements

- The preparation of work electrode

- Electrochemical measurements of HER performance

-Electrochemical measurement and calculation for ECSA

- Electrochemical impedance analysis (EIS)

- Faradic efficiency (FE) test and calculation

- Figures and Tables

-Computational simulations

- Computational Methods 


\section{S1. Experimental Section}

Chemicals. Ammonium molybdate $\left(\left(\mathrm{NH}_{4}\right)_{2} \cdot \mathrm{MoO}_{4}, 99.99 \%\right)$ was purchased from Acros Organics. Ammonium tungsten oxide $\left(\left(\mathrm{NH}_{4}\right)_{2} \cdot \mathrm{WO}_{4}\right.$, $99.99+\%)$ was purchased from Alfa Aesar. Melamine $\left(\mathrm{C}_{3} \mathrm{~N}_{3}\left(\mathrm{NH}_{2}\right)_{3}, 99 \%\right)$, Phosphorous acid $\left(\mathrm{H}_{3} \mathrm{PO}_{4}, 85\right.$ wt. \% in water) and Isopropyl alcohol $\left(\left(\mathrm{CH}_{3}\right)_{2} \mathrm{CHOH}, 99.5 \% \mathrm{AR}\right)$ were purchased from Innochem. Potassium hydroxide (KOH, 99.999\%) was purchased from Aladdin. All chemicals, including Pt/C (Johnson Matthey $20 \mathrm{wt} \% \mathrm{Pt}$ on Vulcan XC-72R) and Nafion (Dupont D5 $20 \mathrm{wt} \%$ ), were used as received without further purification. The water used throughout all experiments was purified through a Millipore system.

Foundational characterization. The morphologies were captured by a scanning electron microscope (SEM, Hitachi S-4800). X-ray diffraction (XRD) was studied with a Bruker D8 Focus using $\mathrm{Cu}-\mathrm{K} \alpha$ radiation, and the measurement was carried out from 10 to $80^{\circ}(2 \theta)$ with a scan rate of $5^{\circ}$ $\mathrm{min}^{-1}$. The Mo, $\mathrm{W}$ and $\mathrm{P}$ concentrations of the samples were conducted on the inductively coupled plasma optical emission spectroscopy (ICP-OES). The specific surface area of the catalysts was evaluated with the BET method using nitrogen adsorption-desorption isotherms measured at $77 \mathrm{~K}$ on Micromeritics MicroActive for ASAP 2460. Raman spectra of the powder samples were recorded with a Renishaw inVia Raman microscope with a laser excitation wavelength of $633 \mathrm{~nm}$. X-ray photoelectron 
spectroscopy (XPS) was performed using Thermo ESCALAB 250Xi.

X-ray absorption data analysis. The $\mathrm{X}$-ray absorption fine structure spectrum for Mo K-edge and W L3-edge EXAFS were recorded at the 1W1B beamline of Beijing Synchrotron Radiation Facility (BSRF) using a $\mathrm{Si}$ (111) double-crystal as monochromator. The storage ring was operated at $2.5 \mathrm{GeV}$, with an average ring current of $200 \mathrm{~mA}$. The data collection was carried out in transmission mode for all samples under ambient conditions. The acquired EXAFS spectra were processed according to the standard procedures using the Athena and Artemis implemented in the IFEFFIT software packages. The EXAFS spectra were obtained by subtracting the post-edge background from the overall absorption and then normalizing with respect to the edge-jump step. Subsequently, the $\chi(\mathrm{k})$ data of were Fourier transformed to real (R) space using a handing windows $\left(\mathrm{dk}=1.0 \AA^{-1}\right)$ to separate the EXAFS contributions from different coordination shells. To obtain the quantitative structural parameters around central atoms, least-squares curve parameter fitting was performed using the Artemis module of IFEFFIT software packages.

$\mathbf{H}_{2}$-TPD test. $\mathrm{H}_{2}$-TPD was carried out using the Chembet TPR/TPD instrument as with $\mathrm{H}_{2}$-TPR. $30 \mathrm{mg}$ catalyst was reduced with at Ar flow at $200{ }^{\circ} \mathrm{C}$ for $1 \mathrm{~h}$ followed at $50{ }^{\circ} \mathrm{C}$. After an adsorption of $\mathrm{H}_{2}$ for $1 \mathrm{~h}$, the catalyst was swept with Ar flow for 20 min until the TCD signal was stable. $\mathrm{H}_{2}$-TPD was conducted at a heating rate of $5{ }^{\circ} \mathrm{C} \mathrm{min}-1$ from 50 to $500{ }^{\circ} \mathrm{C}$, 
and the desorbed $\mathrm{H}_{2}$ was detected by a TCD.

The preparation of work electrode. To prepare the $\mathrm{W}_{0.25} \mathrm{Mo}_{0.75} \mathrm{P} / \mathrm{PNC}$ catalyst ink, $3 \mathrm{mg}$ catalyst and $10 \mu \mathrm{L} 5 \mathrm{wt} \%$ nafion were dispersed into 300 $\mu \mathrm{L}$ water-isopropanol solution with volume ratio of $1: 3$ by sonicating for 1 $\mathrm{h}$ to form a homogeneous ink. Then $10 \mu \mathrm{L}$ ink was drop-casted on the glassy carbon electrode $\left(0.196 \mathrm{~cm}^{2}\right.$, catalyst loading $\left.0.51 \mathrm{mg} \mathrm{cm} \mathrm{cm}^{-2}\right)$. $\mathrm{Ag} / \mathrm{AgCl}\left(\mathrm{N}_{2}\right.$-saturated) was used as the reference electrode, and graphite rod was used as the counter electrode.

Electrochemical measurements of HER performance. Linear sweep voltammetry (LSV) with scan rate of $2 \mathrm{mV} \mathrm{s}^{-1}$ was conducted in $1 \mathrm{M} \mathrm{KOH}$ solution (purged with pure $\mathrm{N}_{2}$ ). A rotation rate of $1600 \mathrm{rpm}$ was used on the working RDE to get rid of the bubbles generated during the test. The polarization curves were processed with iR correction (the specific percentage of the correction is $95 \%$ ). Onset overpotentials were determined based on the beginning of the linear regime in the Tafel plot. Long-term stability tests were carried out by chronoamperometry. For stability test, we chose $\mathrm{H}$-cell to avoid the negative effect from the corrosion of carbon rods during long-term stability tests, $\mathrm{Hg} / \mathrm{HgO}$ was used as the reference electrode and the carbon paper $\left(0.5 \times 0.5 \mathrm{~cm}^{2}\right)$ casted with the catalyst was used as the work electrode.

Electrochemical measurement and calculation for ECSA. The electrochemical active surface areas (ECSAs) were determined by analyses 
of the double-layer capacitance $\left(\mathrm{C}_{\mathrm{dl}}\right)$. $\mathrm{C}_{\mathrm{dl}}$ measurements were measured in a potential range where no faradic processes are observed. We sweep the potential between 0.16 to $0.4 \mathrm{~V}$ (vs. RHE) at varied scan rates ranging from 10 to $300 \mathrm{mV} \mathrm{s}^{-1}$. By plotting the variance in half of the current density $(\mathrm{J})$ between anodic and cathodic sweep $\left(\Delta \mathrm{J}_{1 / 2},\left(\mathrm{~J}_{\mathrm{a}}-\mathrm{J}_{\mathrm{c}}\right) / 2\right)$ at a fixed potential $(0.3 \mathrm{~V}$ vs. RHE) against the scan rate, the slope of the plot can be determined and then divided by Eq. $\mathrm{S} 1$ to obtain the $\mathrm{C}_{\mathrm{dl}}$, which is linearly promotional to the ECSA. These values of $\mathrm{C}_{\mathrm{dl}}$ permit comparison of relative surface activity of different electrodes, particularly in the same electrolyte..$^{1-3}$

$C_{d l}=\frac{1 / 2 \Delta J}{\Delta(\text { Scan Rate })} \quad$ Eq. S1

Electrochemical impedance analysis (EIS). EIS was performed in the range of $1000 \mathrm{kHz}$ to $0.1 \mathrm{kHz}$ to investigate the HER kinetics. EIS were fitted in equivalent circuit where $R s$ is the resistance of solution, $R_{c t}$ is the resistance of charge transfer and $\mathrm{R}$ is the resistance of adsorbed hydrogen intermediates on the metal phosphide.

Faradic efficiency (FE) test and calculation. The Faradic efficiency of HER was measured using chronoamperometry at various potential in an $\mathrm{H}$ type electrochemical cell separated by a Nafion 117 membrane. The area of the working electrode is fixed at $1 \mathrm{~cm}^{2}$. The catalyst ink was dropped onto a dry carbon paper (Sigracet 29BC) with the catalyst loading is 0.67 $\mathrm{mg} \mathrm{cm}{ }^{-2}$. The $\mathrm{H}_{2}$ gas was quantified by a gas chromatograph (GC-2014C) 
equipped with a thermal conductivity detector (TCD) for $\mathrm{H}_{2}$. Ultra-pure argon $(99.999 \%)$ was used as the carrier gas. The average flow rate of $\mathrm{N}_{2}$ was controlled at $10 \mathrm{cc} \mathrm{min}-1$ at the inlet of the electrochemical cell by a standard series mass flow device (S49 32/MT) and measured by a flow meter (Horiba, MT-52) at the exit of the electrochemical cell. GC was calibrated using standard gas mixtures under standard conditions (1 atm, $298 \mathrm{~K})$.

The Faradic efficiency of $\mathrm{H}_{2}$ was calculated as follows: ${ }^{4}$

$$
\mathrm{FE}=\frac{n * V * G * F * P_{0}}{I * R * T_{O} * 60000}
$$

where $\mathrm{n}$ is the number of electrons required to produce a $\mathrm{H}_{2}$ molecule (2); $\mathrm{V}$ is the volume ratio of $\mathrm{H}_{2}$ gas in the $\mathrm{GC}$ sampling loop; $\mathrm{G}$ is the volumetric flow rate; $I$ is the average current in a period $(t)$ of electrocatalysis: $\mathrm{I}=\frac{\int_{0}^{t} I(t) d t}{t} ; \mathrm{F}$ is the Faradic constant $\left(96485 \mathrm{C} \mathrm{mol}^{-1}\right) ; \mathrm{P}_{0}$ is the atmospheric pressure $\left(1.013 * 10^{5} \mathrm{~Pa}\right)$; $\mathrm{R}$ is the ideal gas constant $\left(8.314 \mathrm{~J} \mathrm{~mol}^{-1} \mathrm{~K}^{-1}\right) ; \mathrm{T}_{0}$ is the reaction temperature $(298 \mathrm{~K}) ; 1 \mathrm{cc} \mathrm{min}^{-1}=$ 1/60000 L s ${ }^{-1}$. 


\section{S2. Figures and Tables}
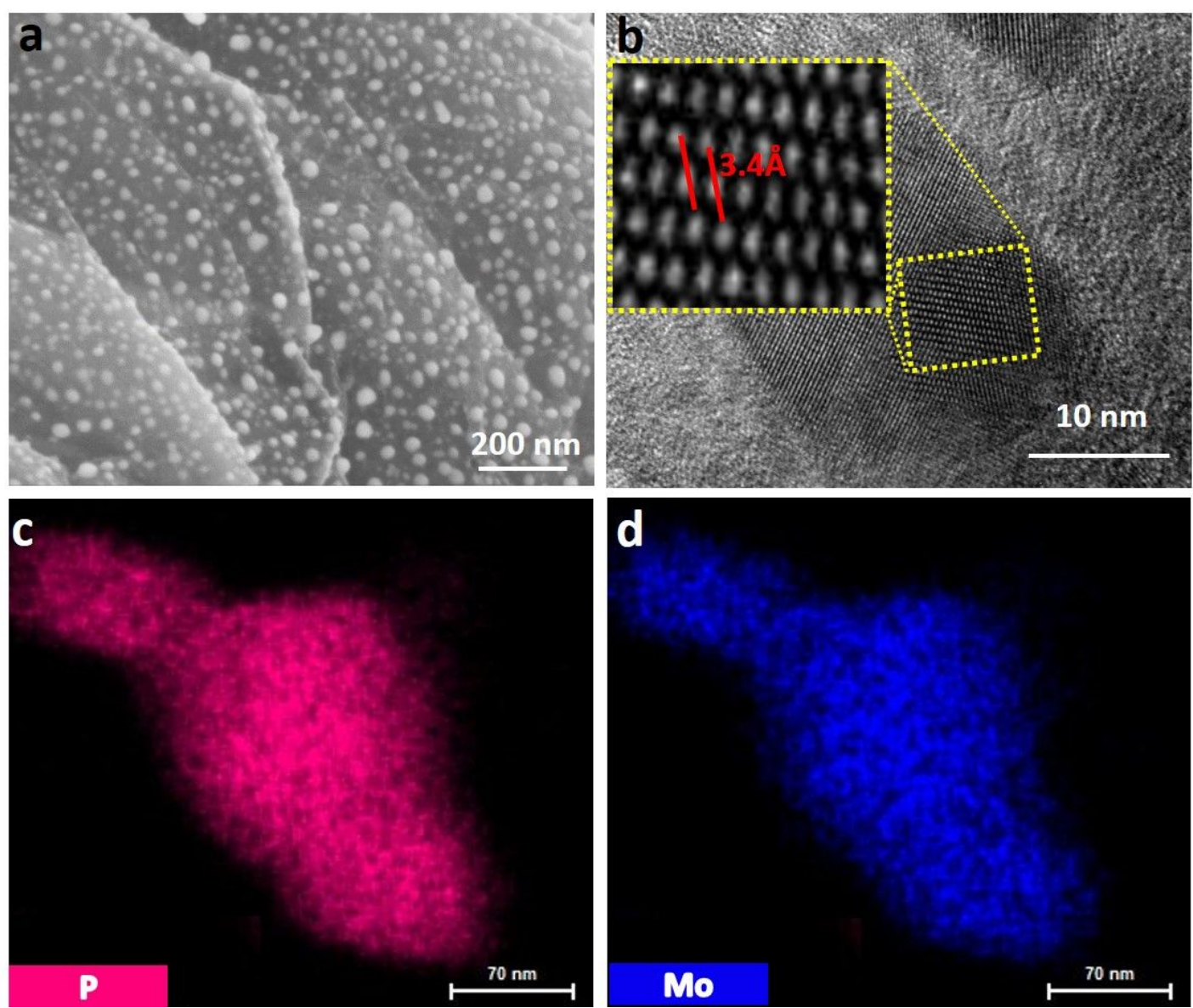

Figure S1. (a) SEM image, (b) High-resolution TEM image, (c-d)

HAADF-STEM with corresponding element mapping images of

$$
\text { MoP/PNC. }
$$



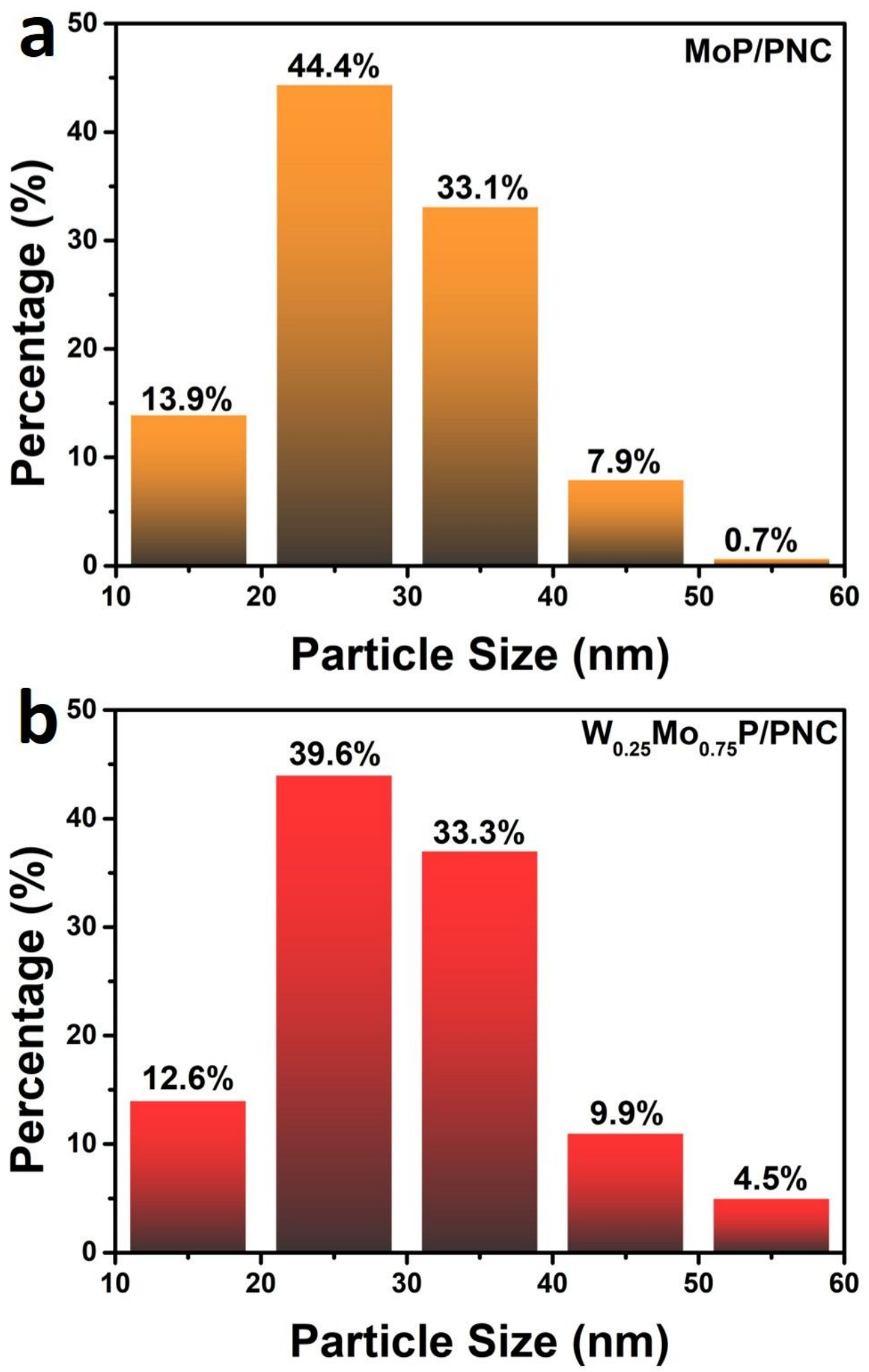

Figure S2. Statistical analyses of particle size distribution of (a) MoP/PNC and (b) $\mathrm{W}_{0.25} \mathrm{Mo}_{0.75} \mathrm{P} / \mathrm{PNC}$ based on counting of particles. 


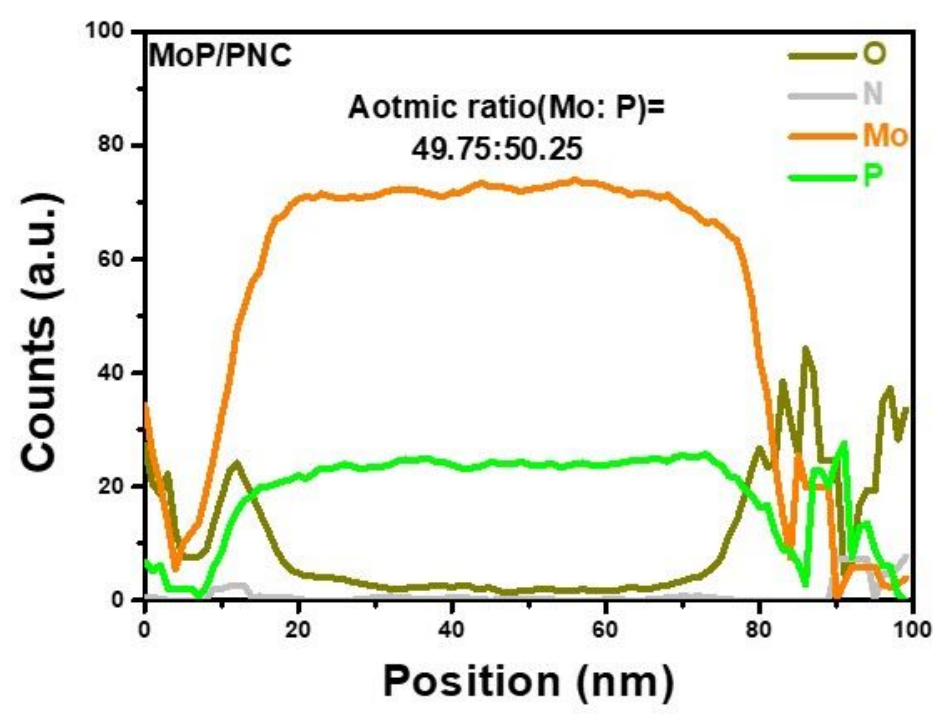

Figure S3. The elemental line scan results of MoP/PNC in HAADFSTEM.

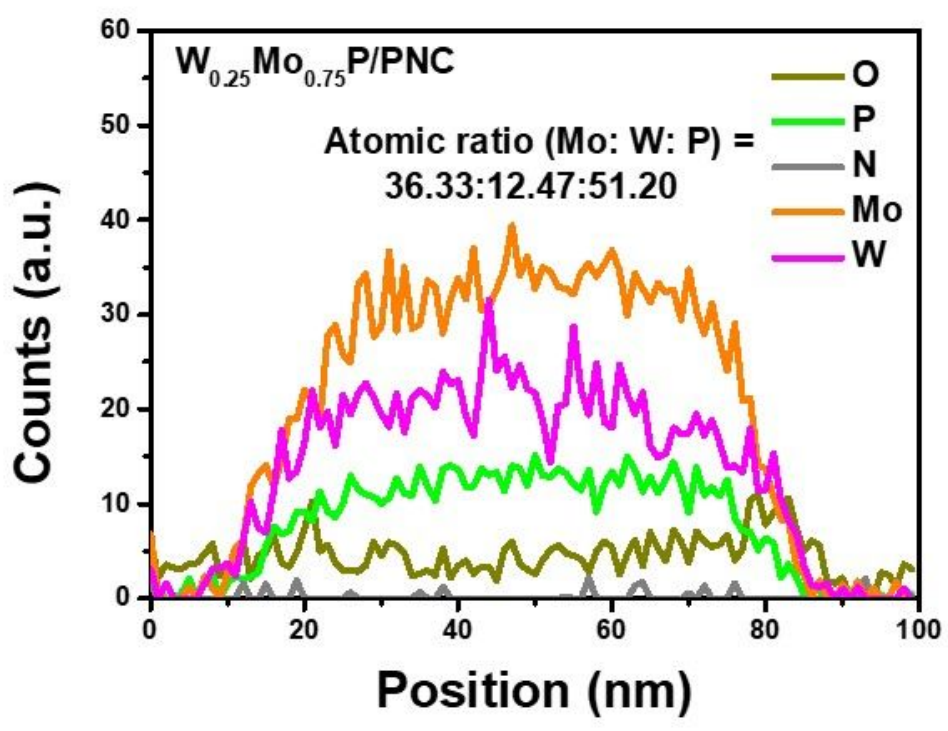

Figure S4. The elemental line scan results of $\mathrm{W}_{0.25} \mathrm{Mo}_{0.75} \mathrm{P} / \mathrm{PNC}$ in HAADF-STEM. 


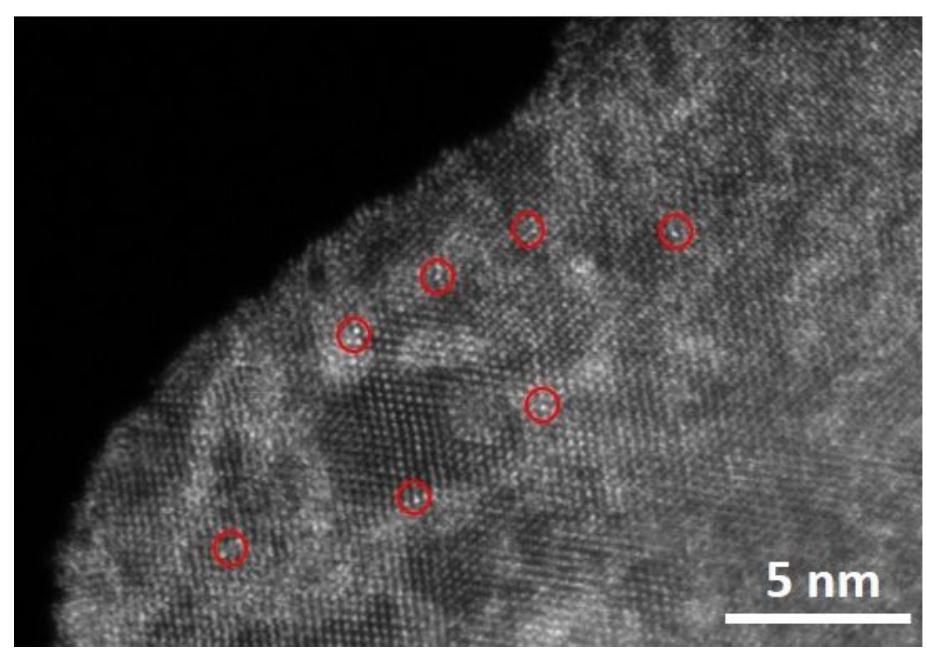

Figure S5. HAADF-STEM element mapping images $\mathrm{W}_{0.25} \mathrm{Mo}_{0.75} \mathrm{P} / \mathrm{PNC}$.

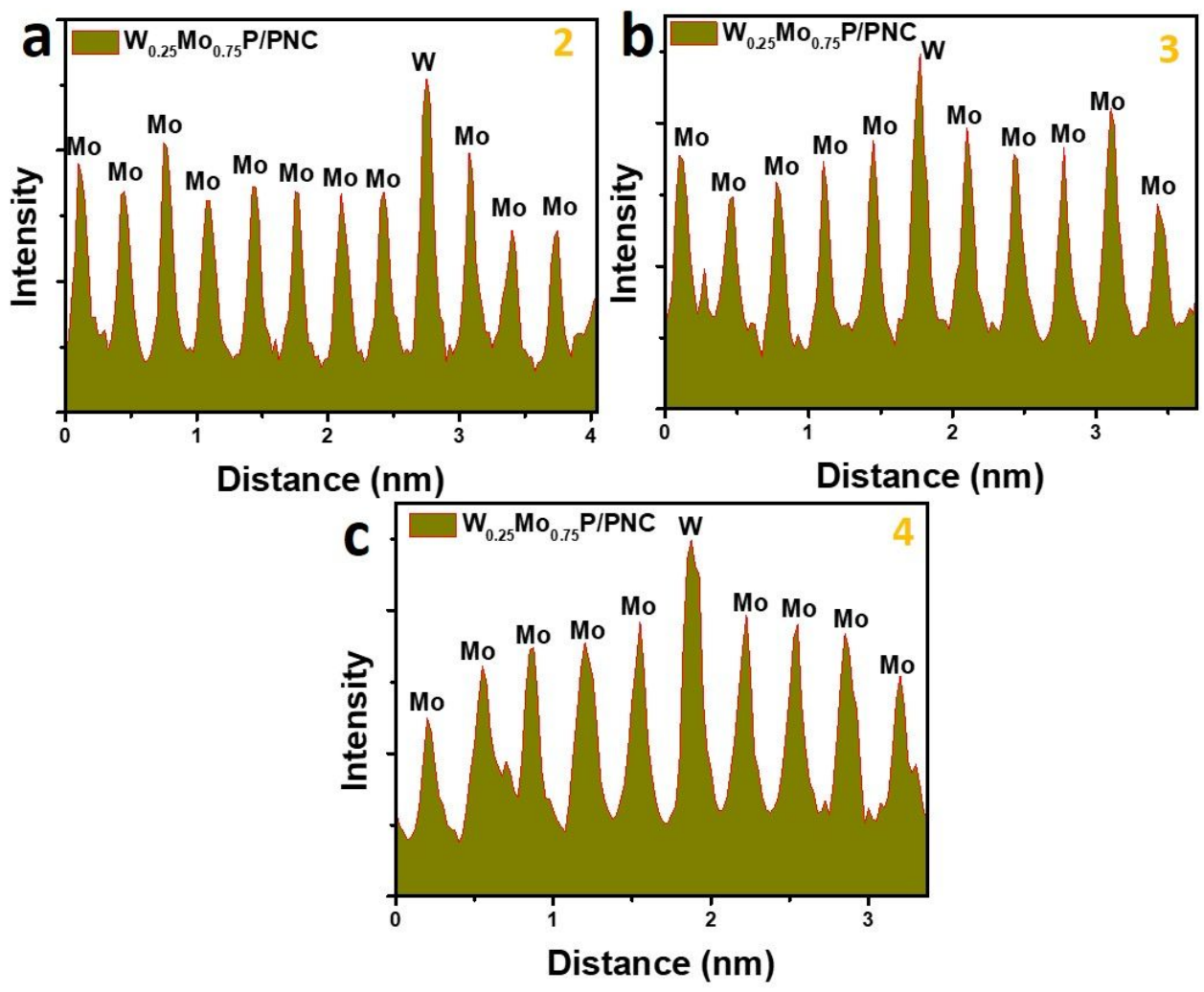

Figure S6. Line profile of the green arrow region in Figure 1e. 


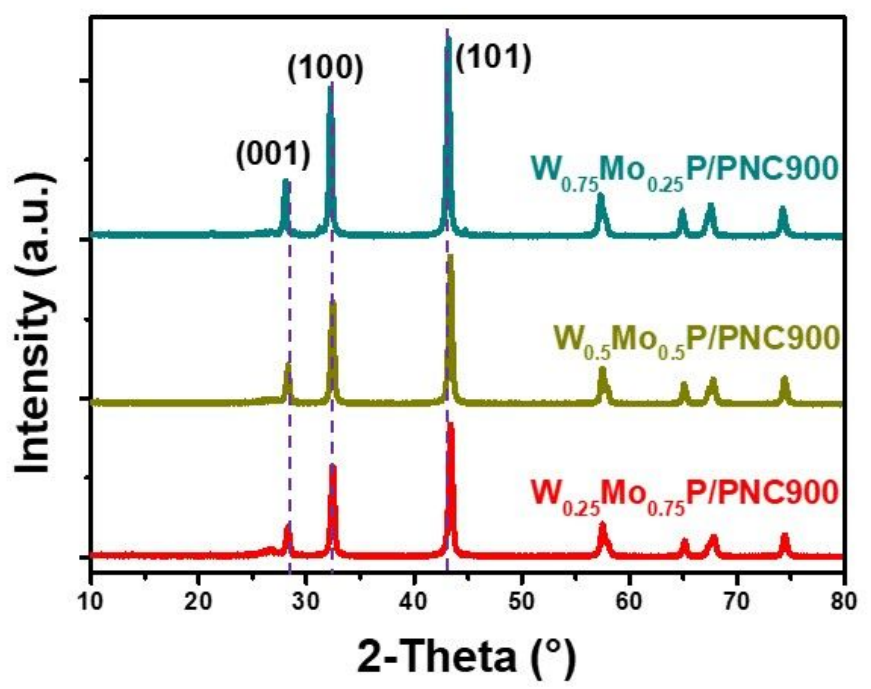

Figure S7. XRD patterns of $\mathrm{W}_{0.25} \mathrm{Mo}_{0.75} \mathrm{P} / \mathrm{PNC}, \mathrm{W}_{0.5} \mathrm{Mo}_{0.5} \mathrm{P} / \mathrm{PNC}$, and $\mathrm{W}_{0.75} \mathrm{Mo}_{0.25} \mathrm{P} / \mathrm{PNC}$.
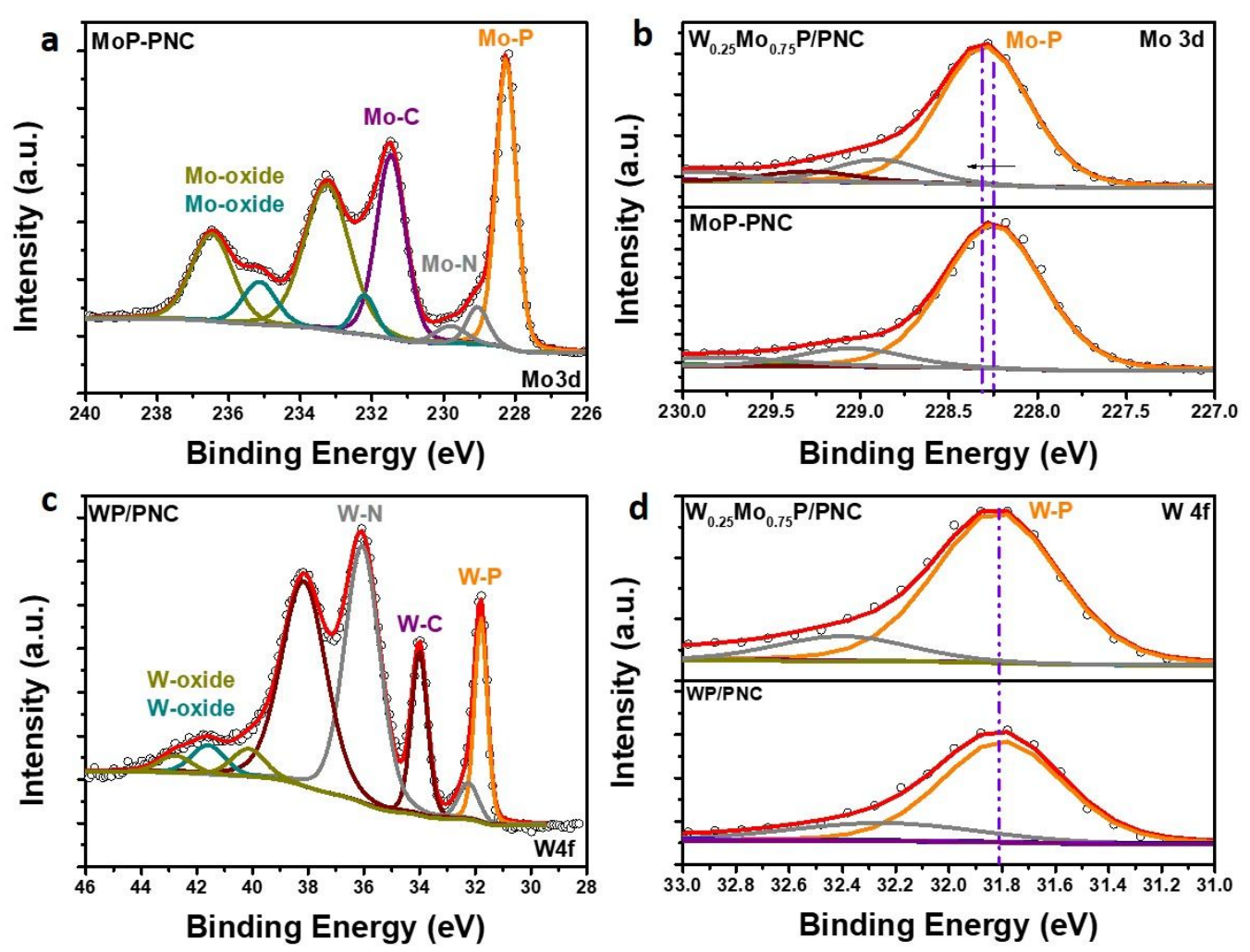

Figure S8. (a) The Mo 3d XPS spectra of MoP/PNC and (b) the comparison for peak of Mo-P; (c) The W 4f XPS spectra of WP/PNC and (d) the comparison for peak of W-P. 


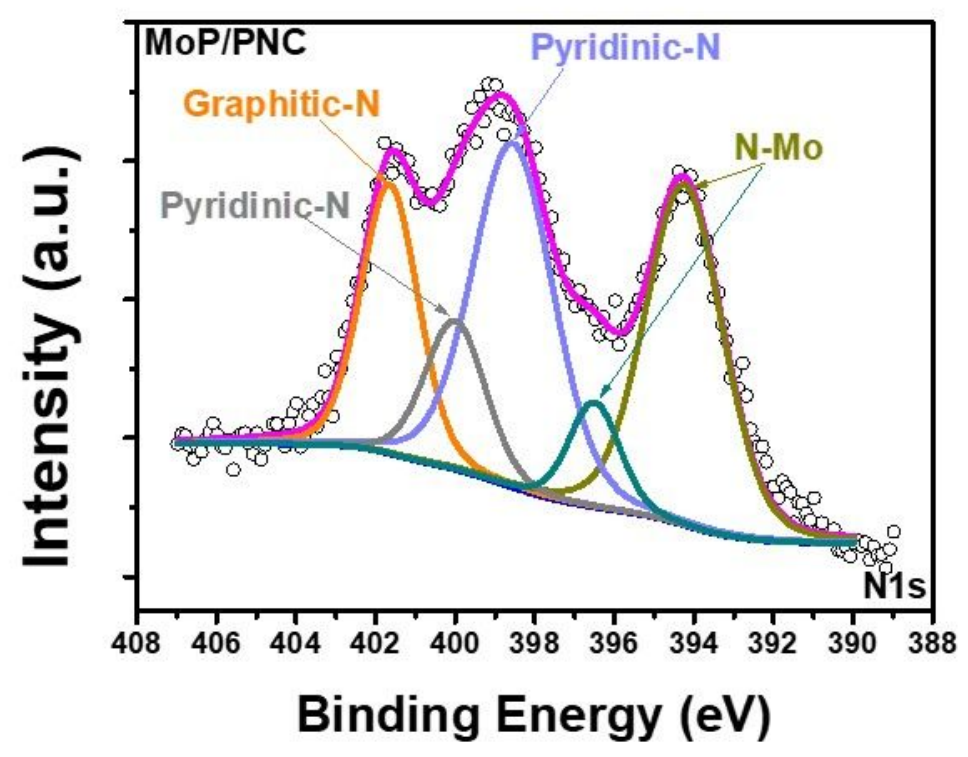

Figure S9. High-resolution N 1s XPS spectra of MoP/PNC.

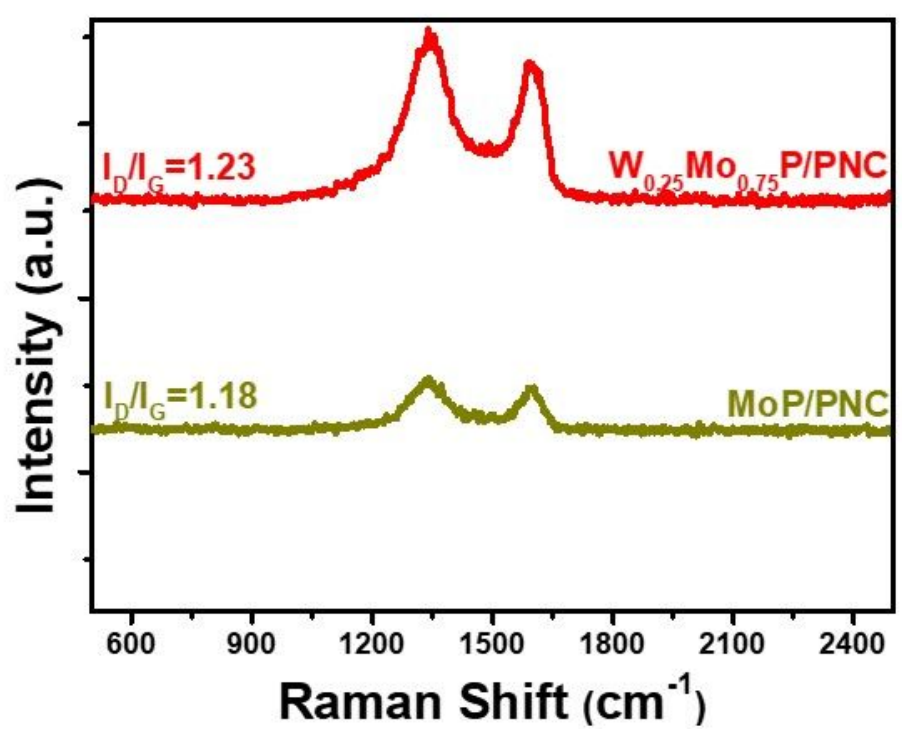

Figure S10. Raman of $\mathrm{MoP} / \mathrm{PNC}$ and $\mathrm{W}_{0.25} \mathrm{Mo}_{0.75} \mathrm{P} / \mathrm{PNC}$. 

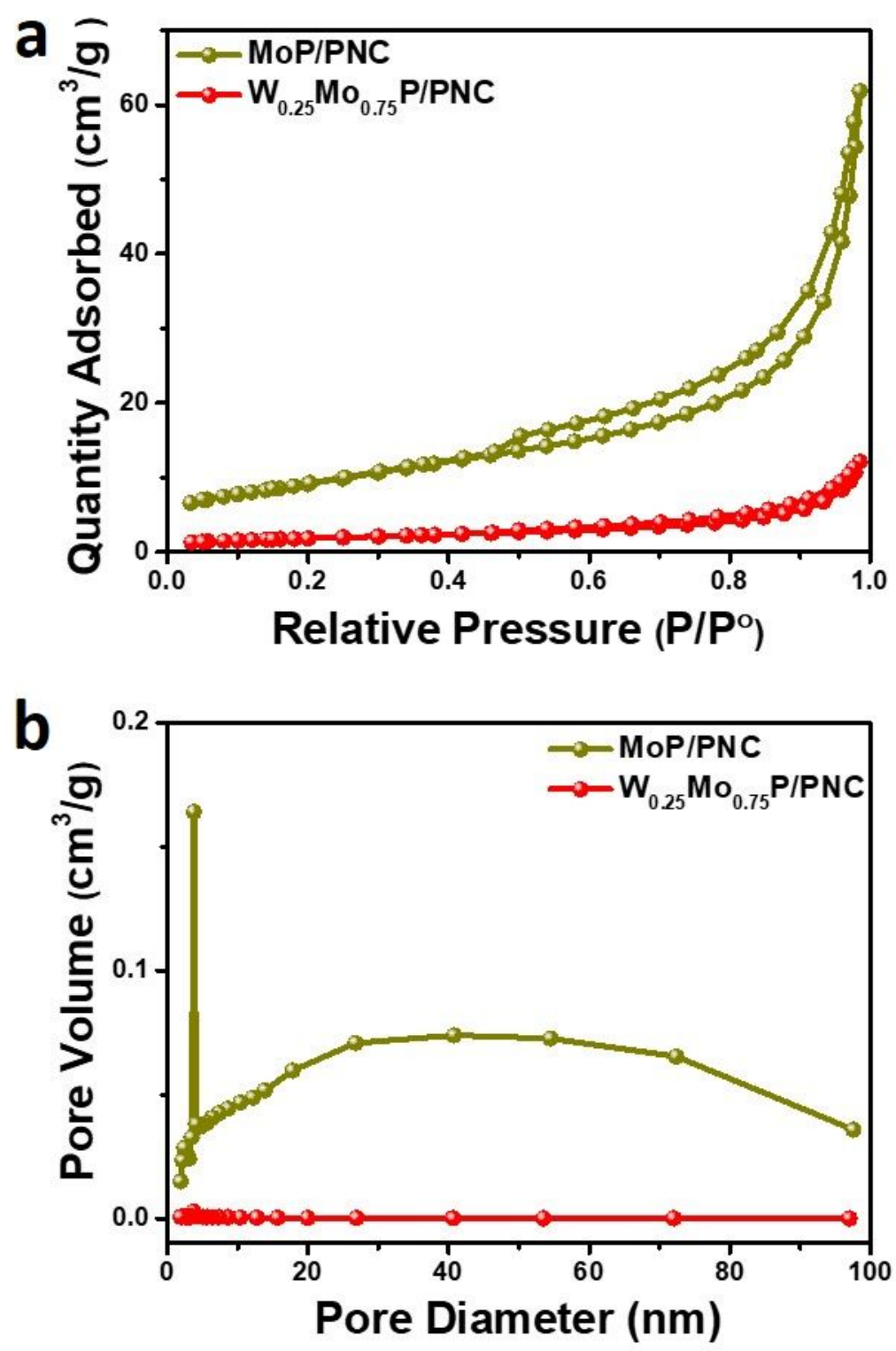

Figure S11. (a) Nitrogen adsorption-desorption curves and (b) the pore diameter distribution of $\mathrm{MoP} / \mathrm{PNC}$ and $\mathrm{W}_{0.25} \mathrm{Mo}_{0.75} \mathrm{P} / \mathrm{PNC}$. 


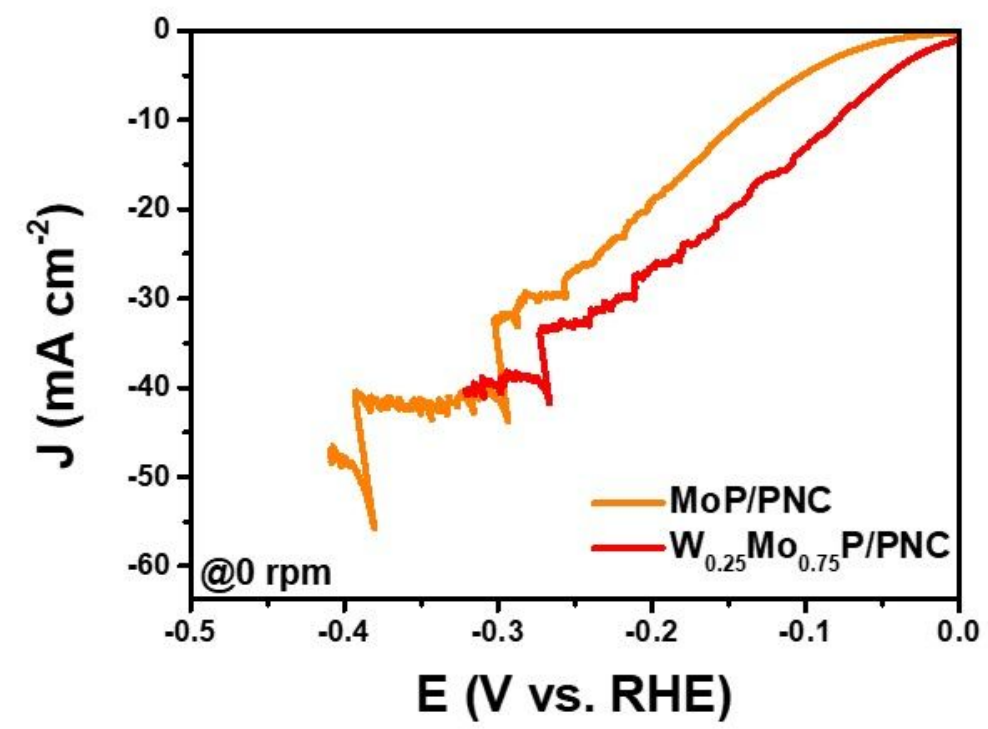

Figure S12. Stationary LSV curves of the MoP/PNC and $\mathrm{W}_{0.25} \mathrm{Mo}_{0.75} \mathrm{P} / \mathrm{PNC}$ catalysts at the rotating speed of $0 \mathrm{rpm}$. As shown in the graph, the LSV curves jitter severely at high overpotential, which is caused by the accumulation of $\mathrm{H}_{2}$ bubbles. In addition, due to a large number of bubbles covering the electrode surface, effective and reliable electrochemical signals could not be obtained. Therefore, to get rid of the $\mathrm{H}_{2}$ bubbles from the surface, we used the rotating electrode operated at $1600 \mathrm{rpm}$ to obtain a more solid and reliable LSV curves. 

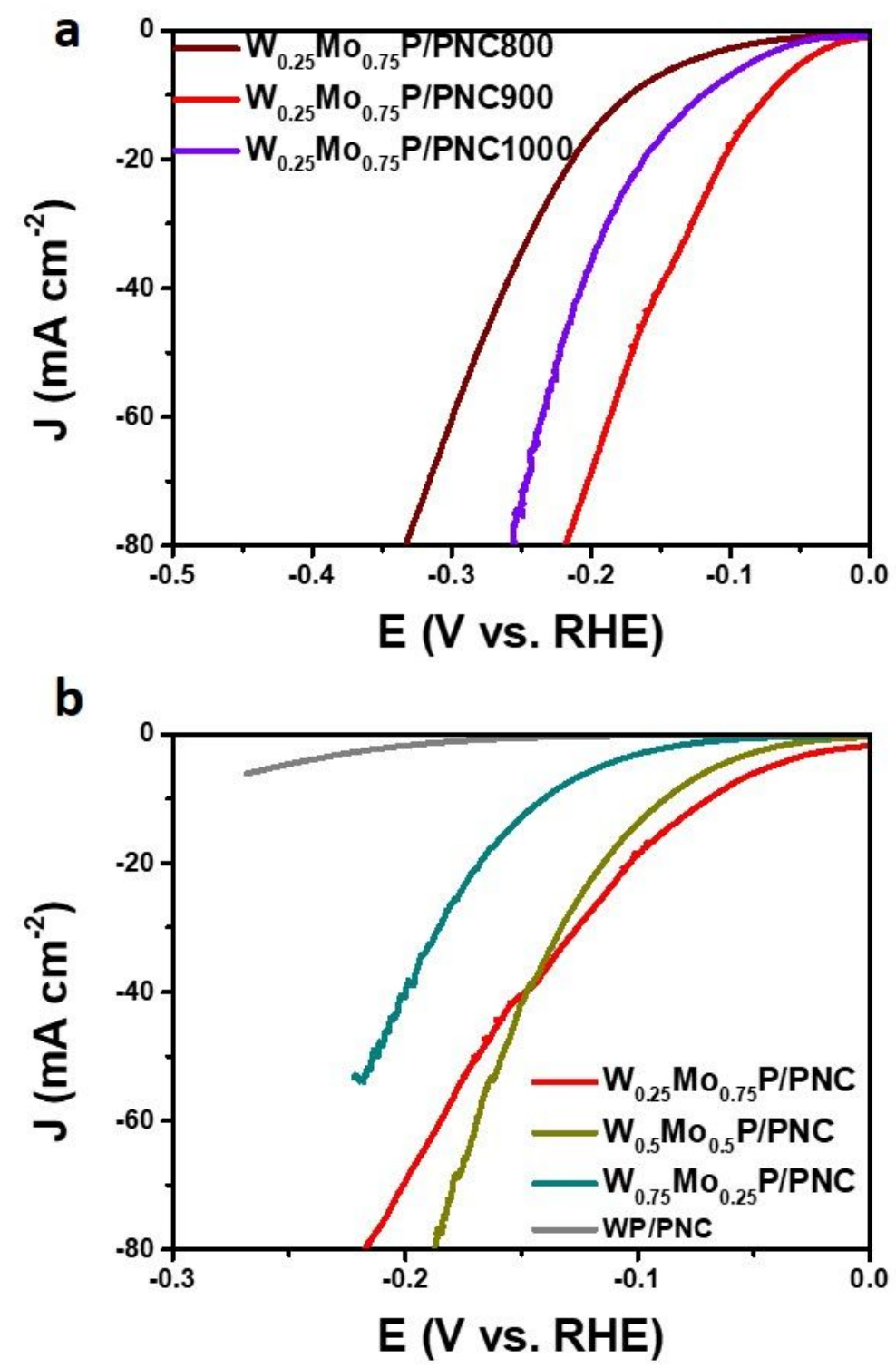

Figure S13. (a) LSV curves of the $\mathrm{W}_{0.25} \mathrm{Mo}_{0.75} \mathrm{P} / \mathrm{PNC}$ catalysts with different pyrolysis temperature, named $\mathrm{W}_{0.25} \mathrm{Mo}_{0.75} \mathrm{P} / \mathrm{PNC} 800$, $\mathrm{W}_{0.25} \mathrm{Mo}_{0.75} \mathrm{P} / \mathrm{PNC} 900$, and $\mathrm{W}_{0.25} \mathrm{Mo}_{0.75} \mathrm{P} / \mathrm{PNC1000}$; (b) LSV curves of $\mathrm{WP} / \mathrm{PNC}$ and $\mathrm{W}_{\mathrm{x}} \mathrm{Mo}_{\mathrm{y}} \mathrm{P} / \mathrm{PNC}$ catalysts with different $\mathrm{W}$ ratios. 


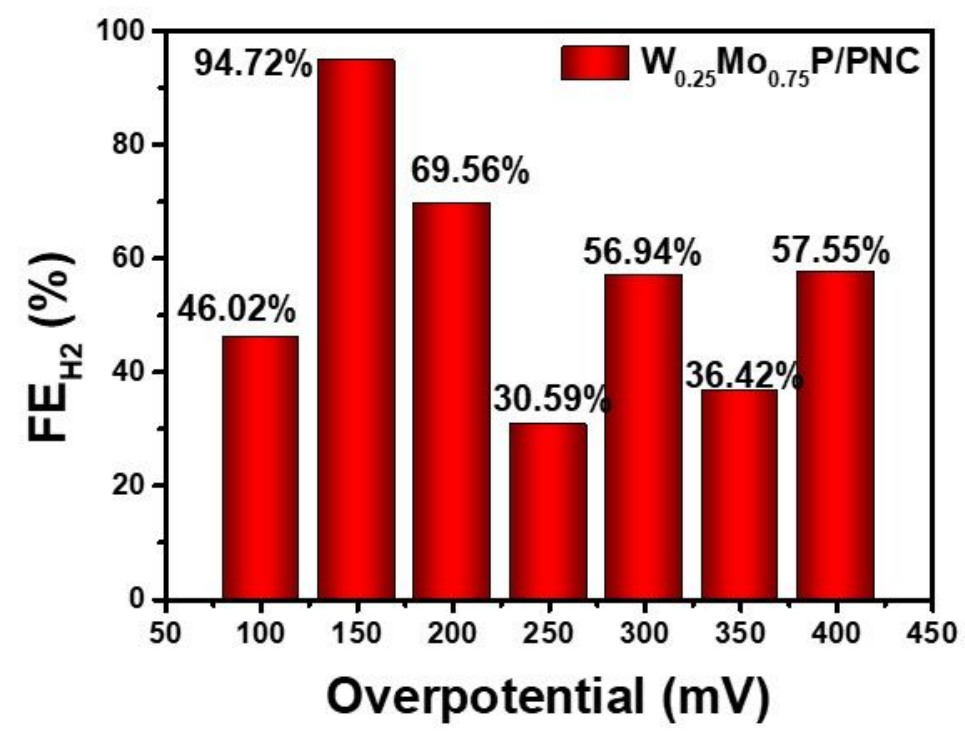

Figure S14. Faradaic efficiencies (FE) toward $\mathrm{H}_{2}$ of $\mathrm{W}_{0.25} \mathrm{Mo}_{0.75} \mathrm{P} / \mathrm{PNC}$ at various applied potentials for $10 \mathrm{~min}$. 

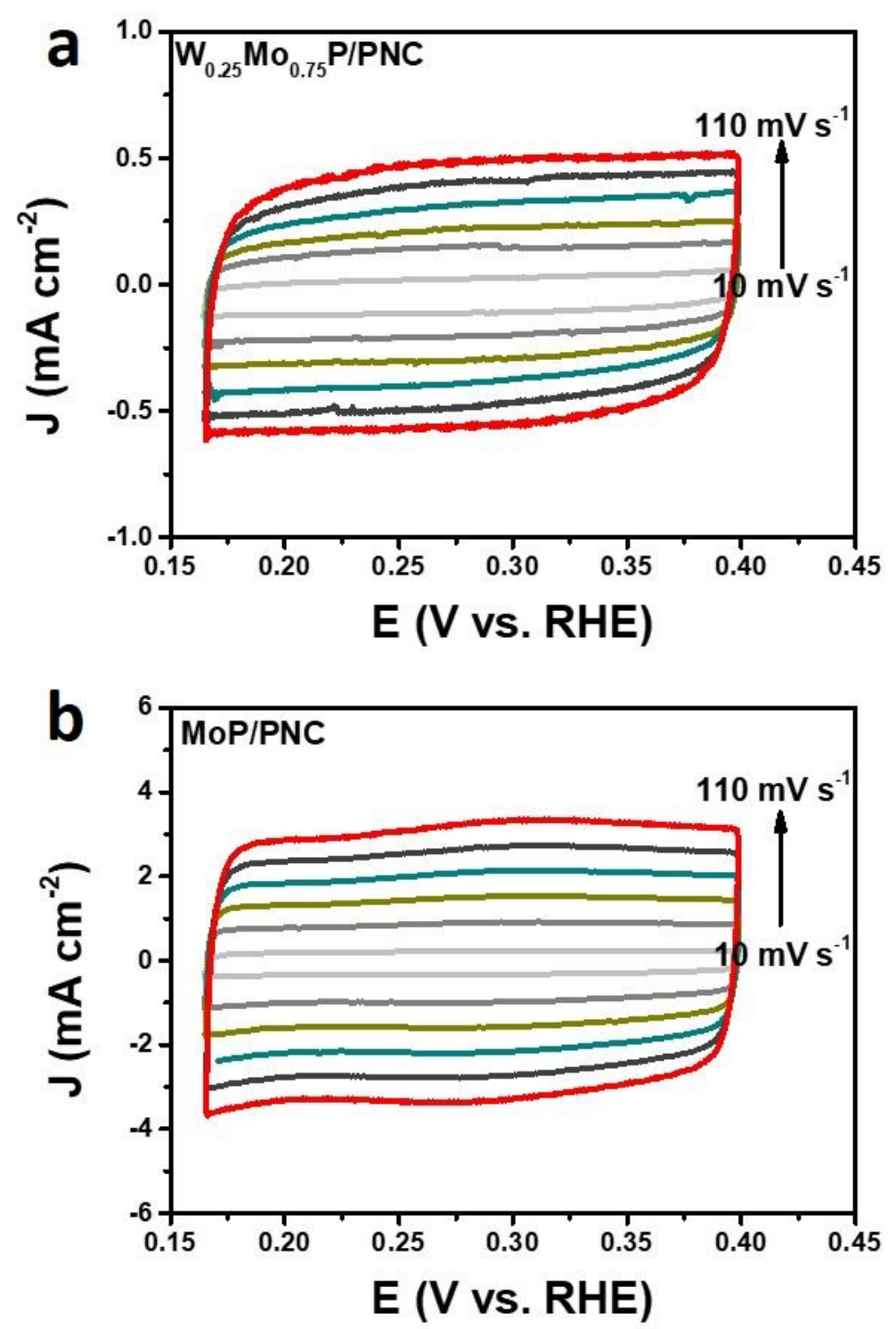

Figure S15. CV curves performed between $0.17 \mathrm{~V}$ and $0.4 \mathrm{~V}$ vs. RHE with scan rate ranging from $10-110 \mathrm{mV} \mathrm{s}^{-1}$. 


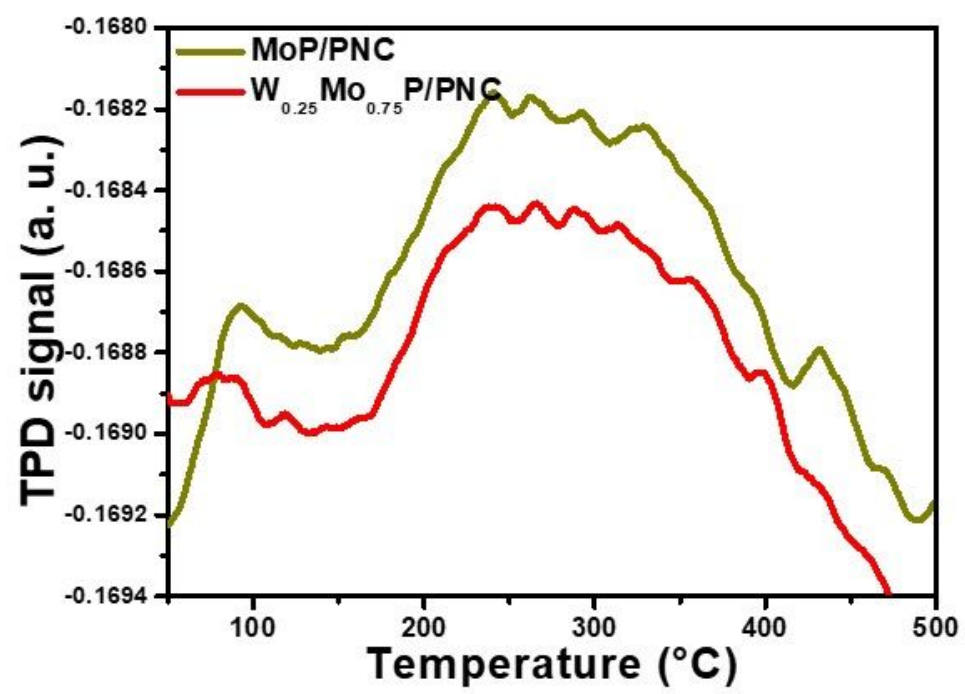

Figure S16. $\mathrm{H}_{2}$-TPD profiles of the phosphide catalysts. 
Table S1. Mo K-edge EXAFS curve Fitting Parameters of $\mathrm{W}_{0.25} \mathrm{Mo}_{0.75} \mathrm{P} / \mathrm{PNC}$.

\begin{tabular}{lcccccc}
\hline \multirow{2}{*}{ sample } & path & $N$ & $R(\AA)$ & $\sigma^{2}\left(\times 10^{-3}\right.$ & $\Delta E_{0}$ & $R$, \\
& & & & $\left.\AA^{2}\right)$ & $(\mathrm{eV})$ & $\%$ \\
\hline \multirow{2}{*}{ Mo foil $^{b}$} & Mo-Mo1 & $\mathbf{8}$ & 2.72 & 4.1 & & \\
& Mo-Mo2 & $\mathbf{6}$ & 3.15 & 4.5 & & 0.3 \\
& Mo-P1 & 4.2 & 2.45 & 3.0 & 1.4 & 0.01 \\
$1^{c}$ & Mo-Mo/W1 & 3.2 & 3.19 & 3.0 & 4.9 & \\
& Mo-P1 & 4.7 & 2.45 & 3.0 & 1.1 & \\
$2^{c}$ & Mo-Mo/W1 & 3.5 & 3.19 & 3.0 & 5.9 & 0.1 \\
\hline
\end{tabular}

${ }^{\mathrm{a}} N$, coordination number; $R$, distance between absorber and backscatter atoms; $\sigma^{2}$, Debye-Waller factor to account for both thermal and structural disorders; $\Delta E_{0}$, inner potential correction; $R$ factor (\%) indicates how well the fitting is. Error bounds (accuracies) that characterize the structural parameters obtained by EXAFS spectroscopy were estimated as $N \pm 20 \%$; $R \pm 1 \% ; \sigma^{2} \pm 20 \% ; \Delta E_{0} \pm 20 \% . S_{0}^{2}$ was fixed to 1.0 . Bold numbers indicate fixed coordination number $(N)$ according to the crystal structure. ${ }^{b}$ Fitting range: $3.0 \leq k(/ \AA) \leq 13.5$ and $1.0 \leq R(\AA) \leq 3.3$. ${ }^{c}$ Fitting range: $2.0 \leq k(/ \AA)$ $\leq 11.0$ and $1.0 \leq R(\AA) \leq 3.3$. 
Table S2. Parameters of impedance analysis performed in $1 \mathrm{M} \mathrm{KOH}$ at $0.17 \mathrm{~V}$ vs. RHE.

\begin{tabular}{llll}
\hline Catalyst & Rs & Rct & $\mathrm{R}$ \\
\hline MoP/PNC900 & 1.5657 & 135.22 & 5.31 \\
$\mathrm{~W}_{0.25} \mathrm{Mo}_{0.75} \mathrm{P} / \mathrm{PNC} 900$ & 1.5423 & 147.65 & 4.56 \\
\hline
\end{tabular}

S3. Computational simulations of the alkaline HER catalyzed by MoP/PNC and W-doped MoP/PNC

\section{S3.1 Computational Methods}

Plane-wave DFT calculations were performed by using the Vienna $A b$ initio Simulation Package (VASP). ${ }^{5,6}$ Pseudopotentials implemented in the projector augmented wave (PAW) method were used to simulate the core electrons. ${ }^{7}$ The revised Perdew-Burke-Ernzerhof (RPBE) form of the generalized gradient approximation (GGA) was chosen as the exchangecorrelation functional. ${ }^{8}$ A plane wave cutoff energy of $450 \mathrm{eV}$ with spin polarization was used in all calculations. A $2 \times 1 \times 1$ Monkhorst-Pack k-point mesh was used for all structures. ${ }^{9}$ All structures were relaxed using a limited memory Broyden-Fletcher-Goldfarb-Shanno (LBFGS) ${ }^{10}$ algorithm until the forces on all atoms were less than $0.03 \mathrm{eV} / \AA$. Kinetic barriers were located by climbing image nudged elastic band (Cl-NEB) method ${ }^{11,12}$. The transition states were further confirmed by the existence of single imaginary vibrational modes along the reaction coordinates.

The atomic models for the MoP/PNC and W-doped MoP/PNC (surface 
composition determined by XPS), as shown in Figure 5a and $\mathrm{b}$ in the main article are periodic unit cells. Their periodicity can be better demonstrated in Figure S17.
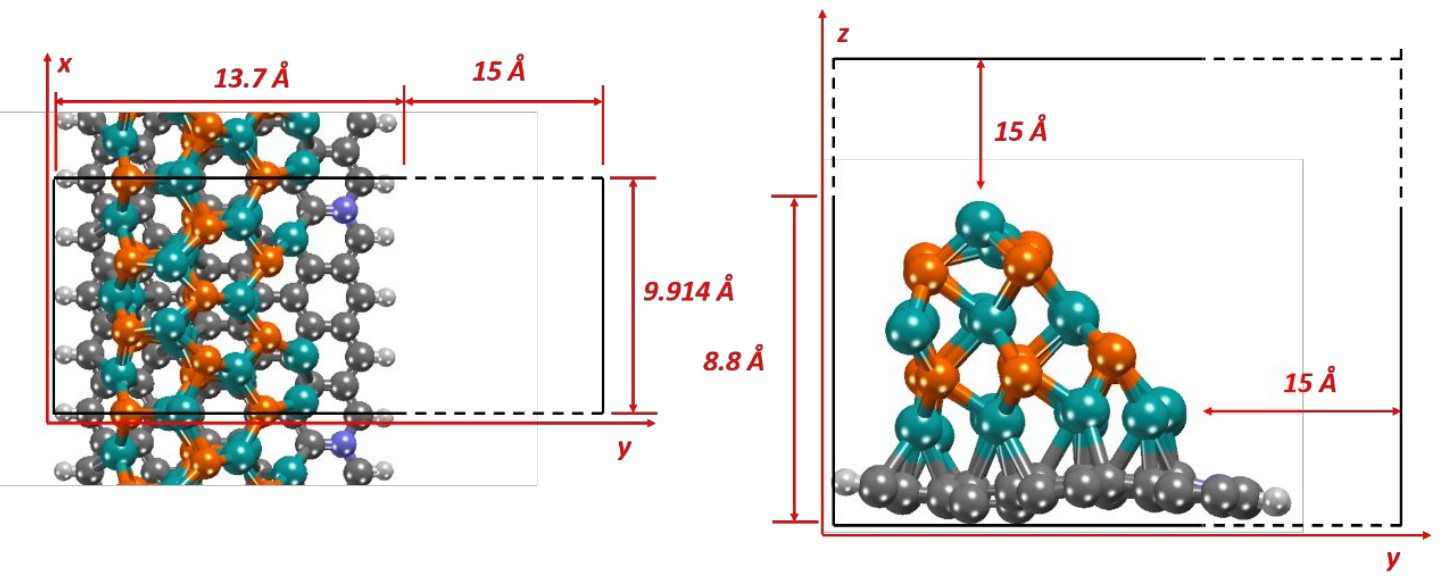

Figure S17. A periodic unit cell of the computational model in this study.

Therefore, these atomic models are continuous only in the $x$-direction, while in the $y$-and $z$-directions, there are at least $15 \AA$ of vacuum space between neighboring unit cells. Such a structure resembles a nanowire and has been adopted in previous studies to represent interfaces between two phases. ${ }^{13}$ Along the $x$-direction, the unit size length was set to be $9.914 \AA$, i. e. four times the width of a carbon ring $(2.479 \AA)$ determined by the RPBE functional. The lattice constant of MoP was calculated to be 3.257 $\AA$, which is rather close to the experimental value of $3.223 \AA .{ }^{14}$ In our model, three primitive unit cells of MoP with a total length of $9.771 \AA$ were matched to the length of four carbon rings (9.914 $\AA$ ) in each unit cell. The MoP nanoparticles must be slightly stretched (1.46\%). After the doping of $\mathrm{W}$, the lattice constant of $\mathrm{W}_{1} \mathrm{Mo}_{2} \mathrm{P}_{3}$ increases to $3.258 \AA$, therefore the $\mathrm{W}_{1} \mathrm{Mo}_{2} \mathrm{P}_{3}$ nanoparticle can almost form a perfect match in size $(9.774 \AA)$ 
with the carbon support $(9.771 \AA)$. During structural relaxations and transition states searches, C, Mo, and W atoms on the leftmost layer (atoms with the smallest $y$ coordinates) were kept fixed while all other atoms are flexible. This treatment is similar to the standard slab model, where the bottom layers of atoms were kept fixed to represent the bulk structure. In our model, the left side of the unit cell represents the bulk oxide phase.

Another detail related to the atomic model is that the $\mathrm{MoP}$ and $\mathrm{W}_{1} \mathrm{Mo}_{2} \mathrm{P}_{3}$ nanoparticles are supported on carbon with Mo or $\mathrm{W}$ atoms having direct contact with $\mathrm{C}$ atoms. Mo or $\mathrm{W}$ can form bonds with $\mathrm{C}$ with cohesive energies of $-0.075 \mathrm{eV}$ and $-0.263 \mathrm{eV}$ per metal atom for $\mathrm{MoP} / \mathrm{PNC}$ and $\mathrm{W}_{1} \mathrm{Mo}_{2} \mathrm{P}_{3} / \mathrm{PNC}$, respectively. On the other hand, $\mathrm{P}$ cannot bond with $\mathrm{C}$. A MoP or W-MoP with P terminations repels the graphene sheet and cannot form a stable adsorbed structure.

\section{S3.2 The calculation of free energy changes}

As summarize in the main article, there are two widely accepted mechanisms for alkaline HER.

Volmer-Heyrovsky Mechanism

(Volmer Step) $\quad \mathrm{H}_{2} \mathrm{O}(\mathrm{l})+{ }^{*}+\mathrm{e}^{-} \rightarrow \mathrm{OH}^{-}+\mathrm{H}^{*}$

(Heyrovsky Step) $\mathrm{H}^{*}+\mathrm{H}_{2} \mathrm{O}(\mathrm{l})+\mathrm{e}^{-} \rightarrow \mathrm{OH}^{-}+\mathrm{H}_{2}(\mathrm{~g})$

(Overall)

$$
\mathrm{H}_{2} \mathrm{O}(\mathrm{l})+\mathrm{e}^{-} \rightarrow \mathrm{OH}^{-}+1 / 2 \mathrm{H}_{2}(\mathrm{~g})
$$

Volmer-Tafel Mechanism

(Volmer Step) $\quad \mathrm{H}_{2} \mathrm{O}(\mathrm{l})+*+\mathrm{e}^{-} \rightarrow \mathrm{OH}^{-}+\mathrm{H}^{*}$ 
(Tafel Step)

$$
2 \mathrm{H}^{*} \rightarrow \mathrm{H}_{2}(\mathrm{~g})+2 *
$$

(Overall)

$$
\mathrm{H}_{2} \mathrm{O}(\mathrm{l})+\mathrm{e}^{-} \rightarrow \mathrm{OH}^{-}+1 / 2 \mathrm{H}_{2}(\mathrm{~g})
$$

An important fact is that the Gibbs free energy change of the overall alkaline HER reaction ((3) or (6)) at $0 \mathrm{~V}$-RHE is 0 . To show this, we need to invoke the definition of the reversible hydrogen electrode (RHE), which defines $\Delta \mathrm{G}$ of the following reaction at $0 \mathrm{~V}$-RHE to be 0 , regardless of the $\mathrm{pH}$ value of the electrolyte:

$$
\begin{aligned}
& \mathrm{H}^{+}+\mathrm{e}^{-} \rightarrow 1 / 2 \mathrm{H}_{2}(\mathrm{~g}) \\
&\left(\Delta_{\mathrm{rxn}} \mathrm{G}=0 \text { at } 0 \mathrm{~V}-\mathrm{RHE}\right)
\end{aligned}
$$

Furthermore, in the electrolyte, protons and hydroxide ions are in constant equilibrium:

$$
\mathrm{H}_{2} \mathrm{O}(\mathrm{l}) \rightarrow \mathrm{H}^{+}+\mathrm{OH}^{-}
$$

$$
\text { ( } \Delta_{\text {rxn }} \mathrm{G}=0 \text { in the electrolyte) }
$$

The addition of (7) and (8) immediately suggests that $\Delta_{\mathrm{rxn}} \mathrm{G}$ of (3) is 0 at 0 V-RHE.

Under potentials of U V-RHE, $\Delta_{\text {rxn }} \mathrm{G}(7)$ should be $\mathrm{U}$ eV, $\Delta_{\text {rxn }} \mathrm{G}(3)=$ $\Delta_{\mathrm{rxn}} \mathrm{G}(7)+\Delta_{\mathrm{rxn}} \mathrm{G}(8)=\mathrm{U}+0=\mathrm{U}$ eV, i. e., $\Delta_{\mathrm{rxn}} \mathrm{G}$ of (3) is $\mathrm{U}$ eV at $\mathrm{U} \mathrm{V}-$ RHE. Therefore, negative potentials are beneficial for the HER reaction, both in acidic and alkaline conditions.

The above conclusion can help to calculate the $\Delta \mathrm{G}$ of elementary reaction steps (1) and (2). At first, the Gibbs free energy of a solvated $\mathrm{OH}^{-}$ion can be calculated according to (3) as 


$$
\mathrm{G}\left[\mathrm{OH}^{-}\right]=\mathrm{G}\left[\mathrm{H}_{2} \mathrm{O}(\mathrm{l})\right]+\mathrm{G}\left[\mathrm{e}^{-}\right]-\mathrm{G}\left[1 / 2 \mathrm{H}_{2}(\mathrm{~g})\right]+\mathrm{U}
$$

(in the unit of eV, at U V-RHE)

Therefore, $\Delta_{\mathrm{rxn}} \mathrm{G}$ of (1) can be calculated as:

$$
\begin{aligned}
& \left.\Delta_{\mathrm{rxn}} \mathrm{G}(1)=\mathrm{G}\left[\mathrm{OH}^{-}\right]+\mathrm{G}\left[\mathrm{H}^{*}\right]-\mathrm{G}\left[\mathrm{H}_{2} \mathrm{O}(\mathrm{l})\right]-\mathrm{G}^{*}\right]-\mathrm{G}\left[\mathrm{e}^{-}\right] \\
& \quad=\mathrm{G}\left[\mathrm{H}_{2} \mathrm{O}(\mathrm{l})\right]+\mathrm{G}\left[\mathrm{e}^{-}\right]-\mathrm{G}\left[1 / 2 \mathrm{H}_{2}(\mathrm{~g})\right]+\mathrm{U}+\mathrm{G}\left[\mathrm{H}^{*}\right]-\mathrm{G}\left[\mathrm{H}_{2} \mathrm{O}(\mathrm{l})\right]-\mathrm{G}\left[{ }^{*}\right]- \\
& \quad \mathrm{G}\left[\mathrm{e}^{-}\right] \\
& \quad=\mathrm{G}\left[\mathrm{H}^{*}\right]-\mathrm{G}\left[^{*}\right]-\mathrm{G}\left[1 / 2 \mathrm{H}_{2}(\mathrm{~g})\right]+\mathrm{U}
\end{aligned}
$$

And $\Delta_{\mathrm{rxn}} \mathrm{G}$ of (2) is exactly

$\Delta_{\text {rxn }} \mathrm{G}(2)=-\mathrm{G}\left[\mathrm{H}^{*}\right]+\mathrm{G}[*]+\mathrm{G}\left[1 / 2 \mathrm{H}_{2}(\mathrm{~g})\right]+\mathrm{U}$

The $\mathrm{G}\left[\mathrm{H}^{*}\right]-\mathrm{G}\left[{ }^{*}\right]-\mathrm{G}\left[1 / 2 \mathrm{H}_{2}(\mathrm{~g})\right]$ term in (10) is exactly the free adsorption energy of $\mathrm{H}^{*}$ on the electrode surface, which can be formally defined as

$\Delta \mathrm{G}_{\mathrm{H}^{*}}=\mathrm{G}\left[\mathrm{H}^{*}\right]-\mathrm{G}\left[{ }^{*}\right]-\mathrm{G}\left[1 / 2 \mathrm{H}_{2}(\mathrm{~g})\right]$

In eq (12), $\mathrm{G}\left[\mathrm{H}^{*}\right]$ and $\mathrm{G}\left[1 / 2 \mathrm{H}_{2}(\mathrm{~g})\right]$ includes the contributions from zeropoint energy (ZPE), heat capacity, and entropy. All of the above terms can be calculated using standard statistical thermodynamics methods described elsewhere. ${ }^{15} \Delta \mathrm{G}_{\mathrm{H}^{*}}$ is also independent of the applied potential and the $\mathrm{pH}$ value, which means that it be conveniently calculated through a gas-phase type calculation. When $\Delta \mathrm{G}_{\mathrm{H}^{*}}$ and the applied potential $\mathrm{U}$ are known, $\Delta_{\mathrm{rxn}} \mathrm{G}$ of the Volmer step and the Heyrovsky step can be calculated from (10) and (11) and the free energy change diagram can be generated. In Figure 5e of the main text, the equilibrium potential ( $0 \mathrm{~V}$-RHE) was adopted. Moreover, in Figure 5e the reaction is assumed to be via the Volmer-Heyrovsky 
pathway, because the Tafel step requires the desorption of two $\mathrm{H}^{*}$, which would be twice as endothermic as the Heyrovsky step and highly unfavorable.

\section{S3.3 Comparison between different forms of $\mathrm{N}$-doped graphene support structures}

In this study, we have used MoP or W-MoP nanoparticles supported on Ndoped graphene as catalysts. In fact, different configurations of $\mathrm{N}$-doped graphene can exist in the support and, as shown in Figure S18, the following four possibilities are considered: pure graphene, $\mathrm{N}$-substituted graphene, pyrrole, and pyridine. In the subsequent text, we use the letters $\mathrm{C}, \mathrm{D}, \mathrm{R}$, and $\mathrm{N}$ to denote these four structures, respectively.

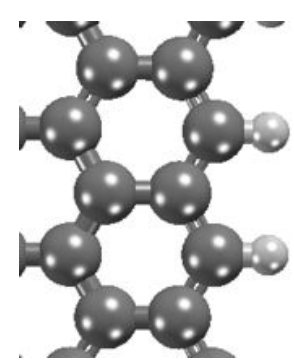

(C)

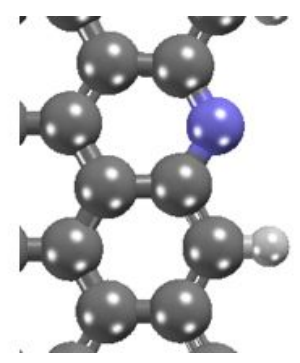

(D)

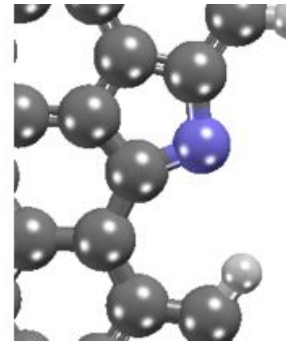

(R)

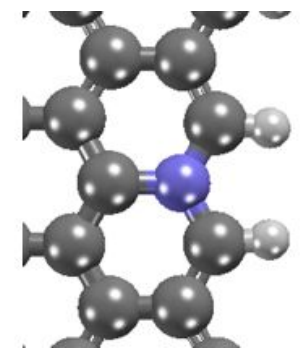

$(\mathrm{N})$

Figure S18. Four different structures of the N-doped graphene support, namely primitive graphene (C), pyridine (D), pyrrole (R), and Nsubstituted graphene $(\mathrm{N})$

MoP or W-MoP supported on these four support structures responds to eight different catalyst structures. We have calculated $\Delta \mathrm{G}_{\mathrm{H}^{*}}$ and $\Delta \mathrm{G}_{\mathrm{B}}$ values on these structures to estimate their catalytic activity. The results 
are summarized in Table S3. In Figure S19 the geometries of the adsorbed $\mathrm{H}^{*}$ and the transition states (TS) of water dissociation are tabulated in Table S4.

Table S3. $\Delta \mathrm{G}_{\mathrm{H}^{*}}$ and $\Delta \mathrm{G}_{\mathrm{B}}$ values of MoP and W-MoP supported on different $\mathrm{N}$-doped graphene structures.

\begin{tabular}{clcc}
\hline No. & Structure & $\begin{array}{l}\Delta \mathrm{G}_{\mathrm{H}^{*}} \\
(\mathrm{eV})\end{array}$ & $\begin{array}{l}\Delta \mathrm{G}_{\mathrm{B}} \\
(\mathrm{eV})\end{array}$ \\
\hline 1 & $\mathrm{MoP} /(\mathrm{C})$ & -0.41 & 0.35 \\
2 & $\mathrm{MoP} /(\mathrm{D})$ & -0.40 & 0.49 \\
3 & $\mathrm{MoP} /(\mathrm{R})$ & -0.30 & 0.56 \\
4 & $\mathrm{MoP} /(\mathrm{N})$ & -0.45 & 0.19 \\
5 & $\mathrm{~W}-\operatorname{doped~MoP~}(\mathrm{W}: \mathrm{Mo}=1: 2) /(\mathrm{C})$ & -0.63 & 0.20 \\
6 & W-doped MoP $(\mathrm{W}: \mathrm{Mo}=1: 2) /(\mathrm{D})$ & -0.61 & 0.22 \\
7 & W-doped MoP $(\mathrm{W}: \mathrm{Mo}=1: 2) /(\mathrm{R})$ & -0.72 & 0.19 \\
8 & W-doped MoP (W: $\mathrm{Mo}=1: 2) /(\mathrm{N})$ & -0.63 & 0.06 \\
9 & W-doped MoP (W: $\mathrm{Mo}=1: 3) /(\mathrm{C})$ & -0.62 & 0.17 \\
10 & W-doped MoP (W: $\mathrm{Mo}=1: 3) /(\mathrm{N})$ & -0.62 & 0.05 \\
\hline
\end{tabular}

Table S4. Illustrations of adsorbed $\mathrm{H}^{*}$ and water dissociation TS on the 10 catalyst structures.

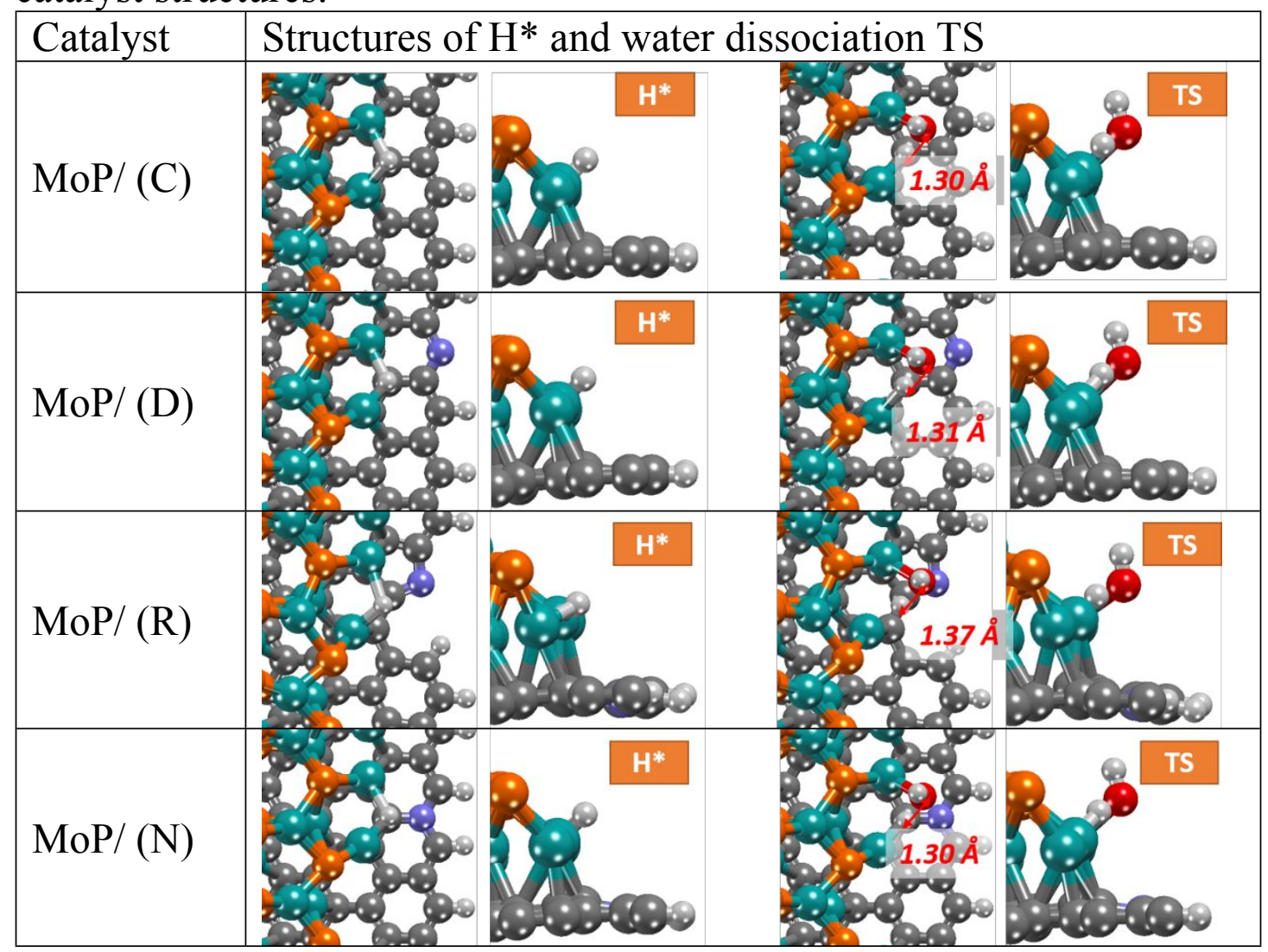




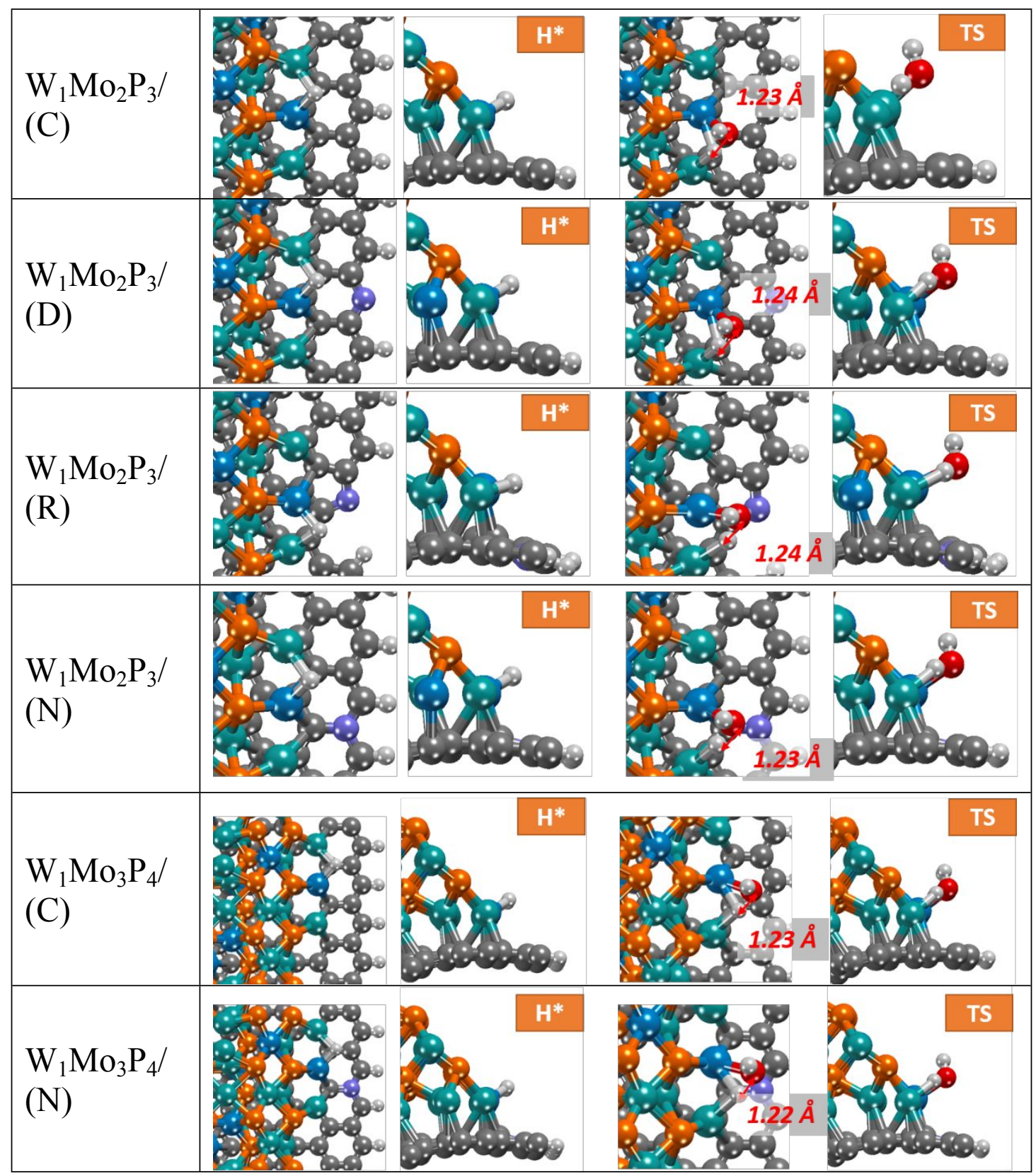

Results in Table S2 suggest that the N-substituted graphene (N) has the lowest water dissociation barriers $\left(\Delta \mathrm{G}_{\mathrm{B}}\right)$ among all supports in both the $\mathrm{MoP}$ and the $\mathrm{W}$-doped MoP cases. Meanwhile, hydrogen adsorption on Nsubstituted graphene supported catalysts is only slightly stronger than on other types of supports. Therefore, we conclude that the (N)-type support has the best performance and used this support structure in the following calculations.

\section{S3.4 $\mathrm{H}^{*}$ coverage effects and the influence of solvent molecules}

In all structures shown in Table $\mathrm{S} 3$, there is only a single $\mathrm{H}^{*}$ atom adsorbed 
on the metal oxide nanoparticle in each unit cell, which corresponds to a very low $\mathrm{H}^{*}$ coverage on the electrode surface. Similarly, the results in Table S3 were calculated under this low-hydrogen-coverage assumption. However, it is well-known that the electrode surface may have a high $\mathrm{H}^{*}$ coverage in HER reaction conditions even in alkaline electrolytes. ${ }^{16} \mathrm{~A}$ portion of the adsorbed $\mathrm{H}^{*}$, which is known as the under-potential deposition of hydrogen $\left(\mathrm{H}_{\text {upd }}\right)$, is rather stable and acts as a spectator during the HER reaction pathways. The existence of $\mathrm{H}_{\text {upd }}$ can lead to an increase in $\Delta \mathrm{G}_{\mathrm{H}^{*}}$ because $\Delta \mathrm{G}_{\mathrm{H}^{*}}$ corresponds to the differential $\mathrm{H}^{*}$ adsorption free energy under the equilibrium $\mathrm{H}^{*}$ coverage.${ }^{17}$ At the same time, the increase in $\Delta \mathrm{G}_{\mathrm{H}^{*}}$ suggests that the actual $\Delta \mathrm{G}_{\mathrm{B}}$ may be higher than the value calculated under low coverage according to the BEP relation.

To gain a more accurate estimation of the $\Delta \mathrm{G}_{\mathrm{H}^{*}}$ and $\Delta \mathrm{G}_{\mathrm{B}}$ values, we have considered higher $\mathrm{H}^{*}$ coverage. As shown in In Figure 5c-d in the main article, the kinetic barriers of water dissociation were calculated with the presence of another $\mathrm{H}^{*}$ adsorbed beside the water molecule. The $\Delta \mathrm{G}_{\mathrm{H}^{*}}$ values in Figure 5e were also based on the differential adsorption free energy of the second $\mathrm{H}^{*}$ as shown in Figure $\mathrm{S} 19$. Since the $\Delta \mathrm{G}_{\mathrm{H}^{*}}$ values ($0.46 \mathrm{eV}$ for $\mathrm{MoP} / \mathrm{PNC}$ and $-0.50 \mathrm{eV}$ for $\mathrm{W}_{1} \mathrm{Mo}_{2} \mathrm{P}_{3} / \mathrm{PNC}$ ) of the second $\mathrm{H}^{*}$ are still less than zero, the actual $\mathrm{H}^{*}$ coverage under real reaction conditions are possibly even higher than the models in Figure S19. However, we have not calculated $\Delta \mathrm{G}_{\mathrm{H}^{*}}$ or $\Delta \mathrm{G}_{\mathrm{B}}$ under higher $\mathrm{H}^{*}$ coverages 
because the adsorption site of additional $\mathrm{H}^{*}$ would be far from the reaction center (i. e. the metal atom on which water or the TS is adsorbed). It was assumed that $\Delta \mathrm{G}_{\mathrm{B}}$ would not change significantly under higher coverages.
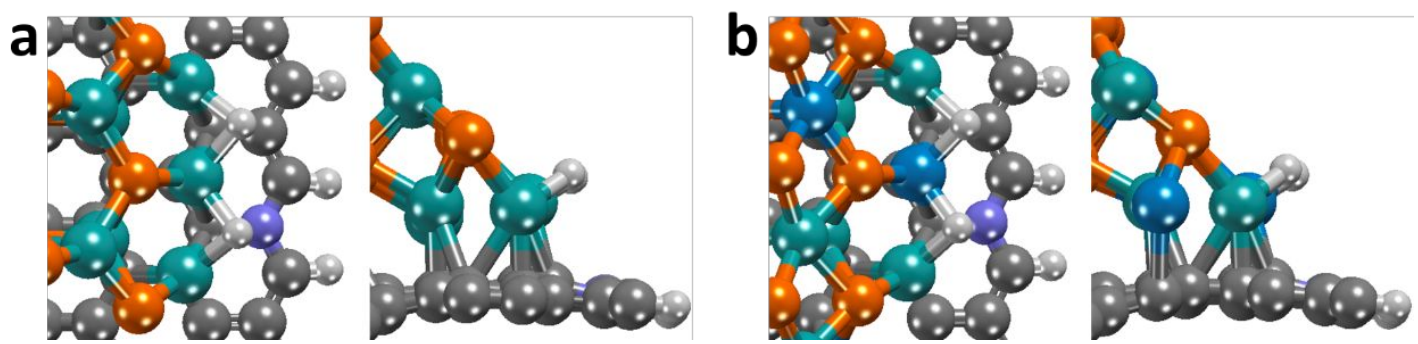

Figure S19. Structures of two $\mathrm{H}^{*}$ adsorbed on (a) $\mathrm{MoP} /(\mathrm{N})$ and (b)

$$
\mathrm{W}_{1} \mathrm{Mo}_{2} \mathrm{P}_{3} /(\mathrm{N})
$$

In the computational models, we have also neglected the presence of the solvent. We found that by placing a water bilayer above the catalyst surface, the $\Delta \mathrm{G}_{\mathrm{H}^{*}}$ values were nearly unaffected (demonstrated in Figure S20), as long as a consistent water layer structure was used.

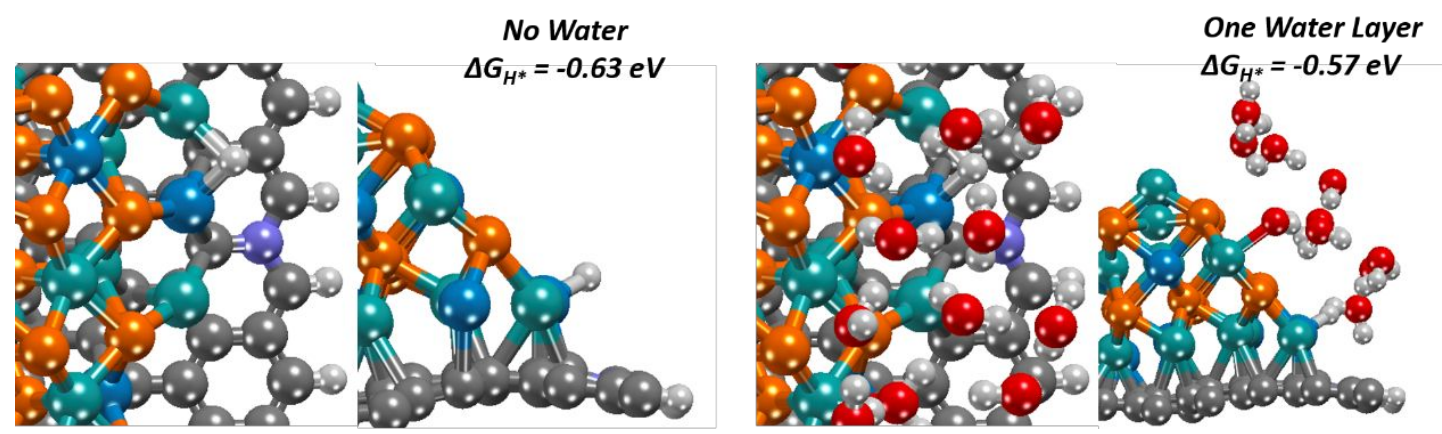

Figure S20. Comparison between the no-water model (used in this study) and the one-layer water model on the $\Delta \mathrm{G}_{\mathrm{H}^{*}}$ value calculated for $\mathrm{H}^{*}$ adsorption on $\mathrm{W}_{1} \mathrm{Mo}_{2} \mathrm{P}_{3} /(\mathrm{N})$.

However, there were difficulties when this model was applied to the calculation of water dissociation barriers. We found that the water-layer would undergo a significant structural change along the water dissociation pathway, leading to unreliable $\Delta \mathrm{G}_{\mathrm{B}}$ values, which are strongly dependent on the initial water-layer structure. Therefore, we decided not to include solvent molecules in the computational models, assuming that the error caused by neglecting the solvent is small.

\section{S3.5 Barriers of the Heyrovsky steps}

Initial states (IS), transition states (TS), and final states (FS) structures of the Heyrovsky steps on both $\mathrm{MoP} /(\mathrm{N})$ and $\mathrm{c} /(\mathrm{N})$ are shown in Figure S21, along with their relative electronic energies. 


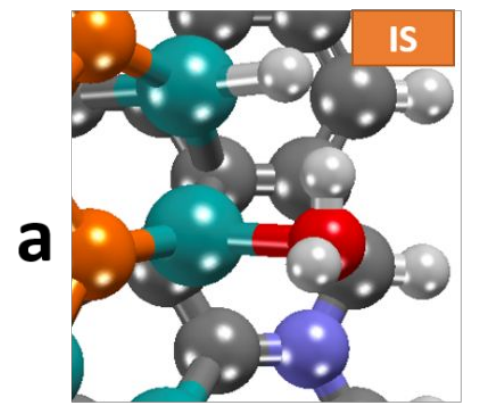

$\mathrm{O} \mathrm{eV}$

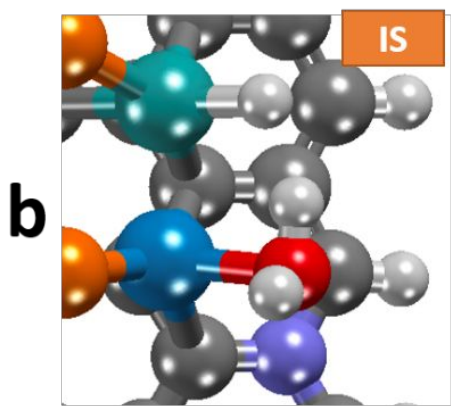

$0 \mathrm{eV}$

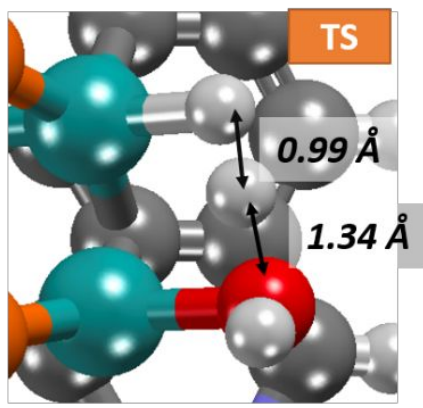

$0.20 \mathrm{eV}$

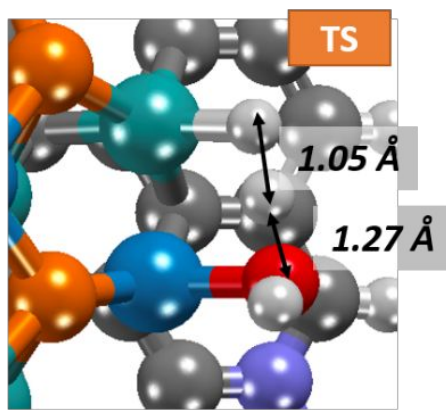

$0.12 \mathrm{eV}$

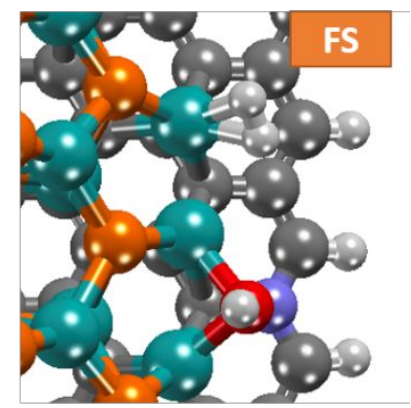

$-0.82 e V$

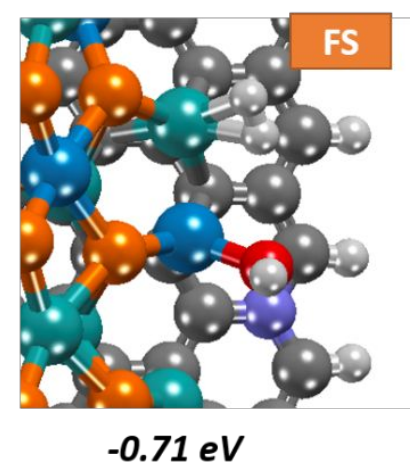

Figure S21. IS, TS, and FS structures and electronic energy change of the Heyrovsky step on (a) $\mathrm{MoP} /(\mathrm{N})$ and (b) $\mathrm{W}_{1} \mathrm{Mo}_{2} \mathrm{P}_{3} /(\mathrm{N})$ 


\section{S3.6 Charge Density Difference Before and After Water Adsorption}
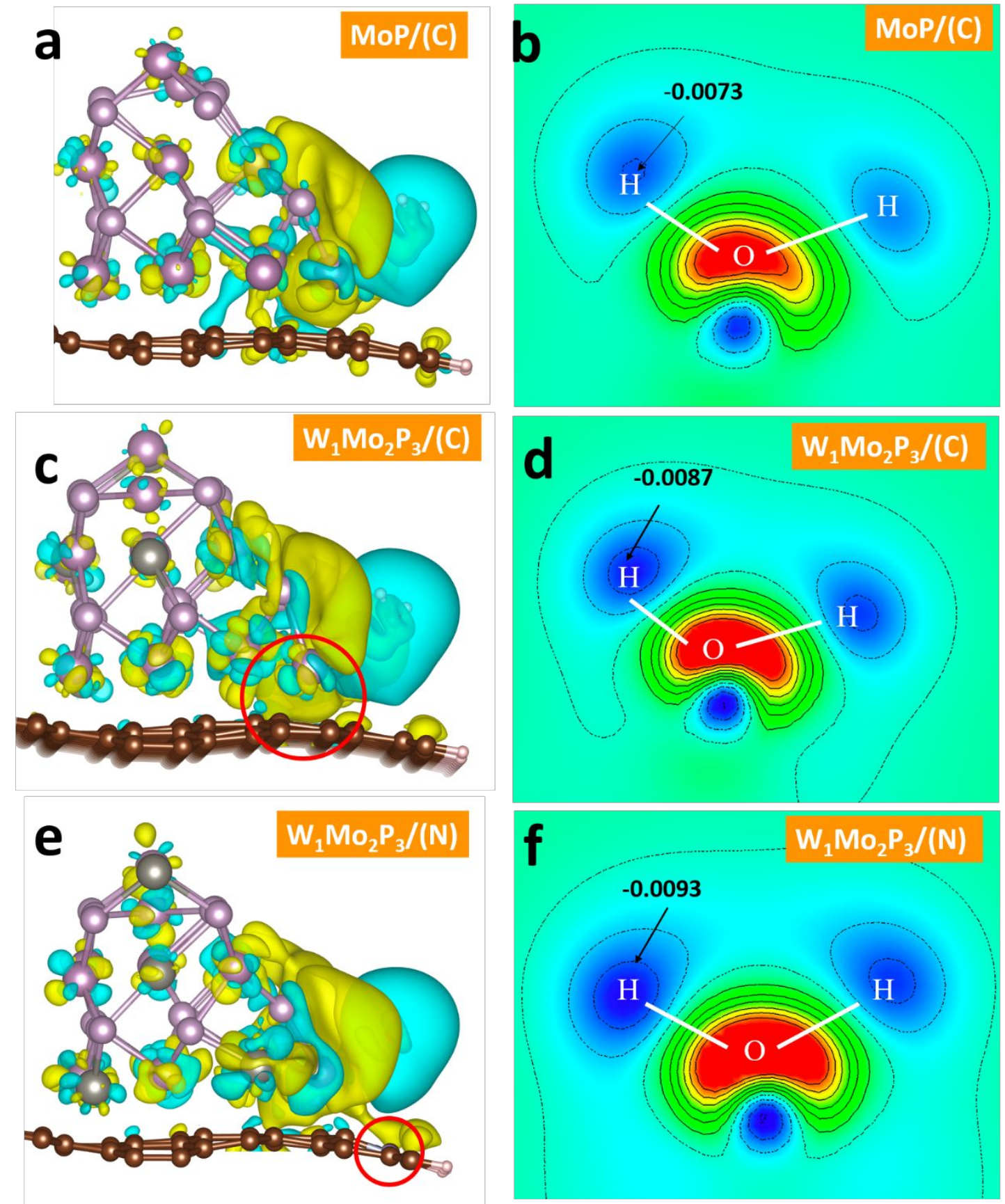

Figure S22. Charge density difference that occurs when a water molecule adsorbs on the catalyst. (a), (c), and (e) are three-dimensional charge density difference plots. In these three plots, yellow means a net accumulation of electrons, while blue means a net loss. The iso-surface level is 0.0002 electron/Bohr ${ }^{3}$. (b), (d), and (f) are two-dimensional charge density difference plots that represent the molecular planes of the adsorbed $\mathrm{H}_{2} \mathrm{O}$. The charge density difference value in the center of one $\mathrm{H}$ atom (the one that is assumed to break from $\mathrm{O}$ in the Volmer step) is given in (b), (d), and (f). (a) and (b) are for the $\mathrm{MoP} /(\mathrm{C})$ catalyst, (c) and 
(d) are for the $\mathrm{W}_{1} \mathrm{Mo}_{2} \mathrm{P}_{3} /(\mathrm{C})$ catalyst, and (e) and (f) are for the $\mathrm{W}_{1} \mathrm{Mo}_{2} \mathrm{P}_{3} /(\mathrm{N})$ catalyst, where the symbols $(\mathrm{C})$ and $(\mathrm{N})$ are explained in Figure S18. Plots were created using the VESTA program. ${ }^{18}$

After water adsorption, the electron density around the $\mathrm{H}$ atom has a negative change (losing electrons), which facilitates their further ionization into $\mathrm{H}^{+}$. The numerical values in Figure S22(b), (d), and (f) correlate well with the catalytic performance of the three catalyst materials, namely $\mathrm{MoP}(\mathrm{C}), \mathrm{W}_{1} \mathrm{Mo}_{2} \mathrm{P}_{3} /(\mathrm{C})$, and $\mathrm{W}_{1} \mathrm{Mo}_{2} \mathrm{P}_{3} /(\mathrm{N})$, because on $\mathrm{W}_{1} \mathrm{Mo}_{2} \mathrm{P}_{3} /(\mathrm{N})$ the $\mathrm{H}$ atom has the largest charge difference, and at the same time the water dissociation barrier is the lowest. Comparison between Figure S22a and c suggests that the doping of $\mathrm{W}$ leads to a slightly larger zone of electron accumulation on the phosphide/graphene interface as highlighted in Figure S22c. In Figure S22e, the doped $\mathrm{N}$ atom and its surrounding $\mathrm{C}$ atoms form a conjugated system (highlighted in the red circle) that draws the charge toward the aromatic plane, which can explain the low water dissociation barrier found in our calculations as listed in Figure 5e and Table S3.

\section{References in the Supporting Information}

1. Huang, X.; Xu, X.; Li, C.; Wu, D.; Cheng, D.; Cao, D., Vertical CoP nanoarray wrapped by N,P-doped carbon for hydrogen evolution reaction in both acidic and alkaline conditions. Advanced Energy Materials 2019, 9, (22), 1803970.

2. Xia, C.; Liang, H.; Zhu, J.; Schwingenschlögl, U.; Alshareef, H. N., Active edge sites engineering in nickel cobalt selenide solid solutions for highly efficient hydrogen evolution. Advanced Energy Materials 2017, 7, (9), 1602089.

3. Zhang, R.; Wang, X.; Yu, S.; Wen, T.; Zhu, X.; Yang, F.; Sun, X.; Wang, X.; Hu, W., Ternary $\mathrm{NiCO}_{2} \mathrm{P}_{\mathrm{x}}$ nanowires as $\mathrm{pH}$-universal electrocatalysts for highly efficient hydrogen evolution reaction. Advanced Materials 2017, 29, (9), 1605502.

4. Yang, H. B.; Hung, S.-F.; Liu, S.; Yuan, K.; Miao, S.; Zhang, L.; Huang, X.; Wang, H.-Y.; Cai, W.; Chen, R.; Gao, J.; Yang, X.; Chen, W.; Huang, Y.; Chen, H. M.; Li, C. M.; Zhang, T.; Liu, B., Atomically dispersed $\mathrm{Ni}(\mathrm{i})$ as the active site for electrochemical $\mathrm{CO}_{2}$ reduction. Nature Energy 2018, 3, (2), 140-147. 
5. Kresse, G.; Furthmüller, J., Efficiency of ab-initio total energy calculations for metals and semiconductors using a plane-wave basis set. Computational Materials Science 1996, 6, (1), 15-50.

6. Kresse, G.; Hafner, J., Ab initio molecular dynamics for liquid metals. Physical Review B 1993, 47, (1), 558-561.

7. Blochl, P. E., Projector augmented-wave method. Physical Review B 1994, 50, (24), 17953-17979.

8. Hammer, B.; Hansen, L. B.; Nørskov, J. K., Improved adsorption energetics within densityfunctional theory using revised Perdew-Burke-Ernzerhof functionals. Physical Review B 1999, 59, (11), 7413-7421.

9. Monkhorst, H. J.; Pack, J. D., Special points for Brillouin-zone integrations. Physical Review B 1976, 13, (12), 5188-5192.

10. Sheppard, D.; Terrell, R.; Henkelman, G., Optimization methods for finding minimum energy paths. The Journal of Chemical Physics 2008, 128, (13), 134106.

11. Sun, H.; Mei, L.; Liang, J.; Zhao, Z.; Lee, C.; Fei, H.; Ding, M.; Lau, J.; Li, M.; Wang, C., Threedimensional holey-graphene/niobia composite architectures for ultrahigh-rate energy storage. Science 2017, 356, (6338), 599-604.

12. Henkelman, G.; Jónsson, H., Improved tangent estimate in the nudged elastic band method for finding minimum energy paths and saddle points. The Journal of Chemical Physics 2000, 113, (22), 99789985.

13. Zhao, Z.-J.; Li, Z.; Cui, Y.; Zhu, H.; Schneider, W. F.; Delgass, W. N.; Ribeiro, F.; Greeley, J., Importance of metal-oxide interfaces in heterogeneous catalysis: A combined DFT, microkinetic, and experimental study of water-gas shift on Au/MgO. Journal of Catalysis 2017, 345, 157-169.

14. Rundqvist, S.; Lundström, T., X-ray studies of molybdenum and tungsten phosphides. Acta Chemica Scandinavica 1963, 17, 37-46.

15. McQuarrie, D. A.; Simon, J. D., Molecular Thermodynamics. Univ Science Books: 1999.

16. Zheng, Y.; Jiao, Y.; Vasileff, A.; Qiao, S.-Z., Hydrogen evolution reaction in alkaline solution: from theory, single crystal models, to practical electrocatalysts Angewandte Chemie International Edition 2018, 57, (26), 7568-7579.

17. Skúlason, E.; Tripkovic, V.; Björketun, M. E.; Gudmundsdóttir, S.; Karlberg, G.; Rossmeisl, J.; Bligaard, T.; Jónsson, H.; Nørskov, J. K., Modeling the electrochemical hydrogen oxidation and evolution reactions on the basis of density functional theory calculations. 2010, 114 (42), 18182-18197v.

18. Momma, K.; Izumi, F., VESTA 3 for three-dimensional visualization of crystal, volumetric and morphology data. Journal of Applied Crystallography 2011, 44, (6), 1272-1276. 